\title{
Operational forecasting of daily summer maximum and minimum temperatures in the Valencia Region.
}

(Natural Hazards, 2014, 70:1055-1076. DOI 10.1007/s11069-013-0861-1:

http://link.springer.com/article/10.1007\%2Fs11069-013-0861-1)

\section{GÓMEZ ${ }^{a}$, M. J. ESTRELA ${ }^{\text {b,c }}$, V. CASELLES ${ }^{a, b}$}

${ }^{a}$ Departament de Física de la Terra i Termodinàmica, Facultat de Física, Universitat de València, Doctor Moliner, 50, 46100 Burjassot, Valencia, Spain.

${ }^{b}$ Laboratorio de Meteorología y Climatología, Unidad Mixta CEAM-UVEG, Charles $R$. Darwin, 14, 46980 Paterna, Valencia, Spain.

${ }^{c}$ Departament de Geografia, Facultat de Geografia i Història, Universitat de València, Avda. Blasco Ibáñez, 28, 46010 Valencia, Spain.

Igor Gómez Doménech

E-mail: godoi@uv.es 


\section{ABSTRACT.}

Extreme temperature events have a great impact on human society. Thus, knowledge of summer temperatures can be very useful both for the general public and for organisations whose workers operate in the open. An accurate forecasting of summer maximum and minimum temperatures could help to predict heat-wave conditions and permit the implementation of strategies aimed at minimizing the negative effects that high temperatures have on human health. The objective of this work is to evaluate the skill of the RAMS model in determining daily summer maximum and minimum temperatures in the Valencia Region. For this, we have used the real-time configuration of this model currently running at the CEAM Foundation. This operational system is run twice a day, and both runs have a three-days forecast range. To carry out the verification of the model in this work, the information generated by the system has been broken into individual simulation days for a specific daily run of the model. Moreover, we have analysed the summer forecast period from $1^{\text {st }}$ June to $31^{\text {st }}$ August for 2007, 2008, 2009 and 2010. The results indicate good agreement between observed and simulated maximum temperatures, with RMSE in general near $2{ }^{\circ} \mathrm{C}$ both for coastal and inland stations. For this parameter, the model shows a negative bias around $-1.5^{\circ} \mathrm{C}$ in the coast while the opposite trend is observed inland. In addition, RAMS also shows good results in forecasting minimum temperatures for coastal locations, with bias lower than $1{ }^{\circ} \mathrm{C}$ and RMSE below $2{ }^{\circ} \mathrm{C}$. However, the model presents some difficulties for this parameter inland, where bias higher than $3{ }^{\circ} \mathrm{C}$ and RMSE of about $4{ }^{\circ} \mathrm{C}$ have been found. Besides, there is little difference in both temperatures forecasted within the two daily RAMS cycles and that RAMS is very stable in maintaining the forecast performance at least for three forecast days. 
Keywords: mesoscale modeling, operational forecasting, heat-waves, summer temperatures. 


\section{Introduction.}

The Valencia Region (western Mediterranean area) (Fig. 1) is especially sensitive to certain meteorological hazards from severe weather phenomena, due to its climatic characteristics and geographic situation (Gómez-Tejedor et al., 1999; Pastor et al. 2001; Pastor et al., 2010; Estrela et al., 2007; Estrela et al, 2008; Gómez et al. 2007; Gómez et al., 2009a; Gómez et al., 2009b; Gómez et al., 2010; Gómez et al., 2011; Gómez et al., 2012). The area's typical Mediterranean climate, characterized by high summer temperatures, permits record maximum temperatures exceeding $30^{\circ} \mathrm{C}$, as well as record minimum temperatures exceeding $20^{\circ} \mathrm{C}$, during so-called tropical nights (Miró et al., 2006; Estrela et al., 2007; Estrela et al., 2008). Increasing concern for public health in relation to extreme maximum and minimum temperature episodes in summer has motivated the implementation of an operational meteorological, forecast and warning system for high temperatures in the Valencia Region within the collective agreement between the General Direction of Public Health within the Regional Government of Valencia and the Meteorology and Climatology Programme at the CEAM (Centro de Estudios Ambientales de Mediterráneo) Foundation (Estrela et al., 2007; Estrela et al., 2008). This tool has been added to the meteorological real-time forecasting system running at the CEAM Foundation (Gómez et al., 2007; Gómez et al., 2010), which is based on the Regional Atmospheric and Modeling System (RAMS) (Pielke et al., 2002; Cotton et al., 2003). This meteorological forecast and warning system uses the RAMS daily maximum and minimum temperatures forecasted by the model to detect high-temperature hazard levels for the thermo-climatic areas in which the Valencia Region has been divided (Miró et al., 2006; Estrela et al., 2007; Estrela et al., 2008). These levels are then used to generate high-temperature hazard-level maps which are displayed in a user-friendly way on the web page of the Meteorology and 
Climatology Programme at the CEAM Foundation (http://www.ceam.es/ceamet/vigilancia/temperatura/verano/olas_calor.html). The General Direction of Public Health within the Regional Government of Valencia utilizes this information to monitor and evaluate the potential risk to human health and activate the established protocol to provide the population with the corresponding social and public health services.

The aim of the current work is to investigate the skill of the RAMS model in forecasting daily maximum and minimum temperatures during the summer period over the Valencia Region, in order to quantify the RAMS errors with respect to these magnitudes. In this paper, we present the results of the operational CEAM-RAMS implementation assessment for determining these magnitudes. The results obtained are based on a systematic comparison between RAMS-simulated maximum and minimum temperatures and observations at both the agro-climatic stations in the Instituto Valenciano de Investigaciones Agrarias network (Valencian Agricultural Research Institute, IVIA, 2003) and the CEAM Foundation meteorological station network. The complexity of the area of study in terms of diversity of climatic and geophysical characteristics has obliged us to disaggregate the available data and analyse the behaviour of the model according to the station location. Therefore, IVIA and CEAM data are processed for each station separately.

Within the Mediterranean area, different systems have been implemented to forecast extreme temperature, such as that of Bartzokas et al. (2010) for northwest Greece, or the one implemented by Federico (2011) for the Calabria region (southern Italy). In the first case, using the MM5 model (Dudhia, 1993), the daily maximum air temperature was slightly overestimated by the model, while minimum temperature was significantly overestimated. This overestimation was strongest for inland areas, where bias values up to 
$6{ }^{\circ} \mathrm{C}$ were observed. Federico (2011), using an optimal interpolation analysis, reproduced low RMSE errors, around $2{ }^{\circ} \mathrm{C}$ for minimum temperatures and slightly higher values for the maximum. In this study, the highest values both for Bias and RMSE were also located inland.

To characterize the behaviour of RAMS in determining maximum and minimum summer temperatures in the Valencia Region, we have stored the values generated by the model simulations for the CEAM and IVIA weather stations for the 2007, 2008, 2009 and 2010 summer season. The evaluation presented in this study is based on the simulations for these periods. The rest of the paper is organized as follows: Section 2 gives a brief description of the RAMS real-time forecasting configuration used to provide the maximum and minimum temperatures utilized within the meteorological forecast and warning system for high temperatures. Details on the evaluation process are included in Section 3. In Section 4 the results obtained for the individual station evaluation are given. Finally, Section 5 contains the concluding remarks.

\section{CEAM-RAMS real-time forecasting system.}

The RAMS model (Pielke et al., 2002; Cotton et al., 2003) has been used at the CEAM Foundation for different research studies (Salvador et al. 1997; Salvador et al., 1999; Gómez-Tejedor et al., 1999; Palau et al., 2005; Pastor et al., 2001; Pérez-Landa et al., 2007). The results obtained have provided us with the necessary know-how to develop and implement a meteorological forecasting system based on running the RAMS model operationally (Gómez et al, 2007; Gómez et al, 2010).

In the CEAM real-time forecasting system, the three-dimensional, non-hydrostatic mode of the RAMS model in its version 4.4 has been used. Extensive information about RAMS can be found in Pielke et al. (2002) and Cotton et al. (2003). A series of two-way 
interactive nested domains were configured at increasing horizontal grid spacing using three domains of 48, 12 and $3 \mathrm{~km}$, respectively (Fig. 2). The vertical discretization is a 24level stretched vertical coordinate with a $50 \mathrm{~m}$ spacing near the surface increasing gradually up to $1000 \mathrm{~m}$ near the model top at $11000 \mathrm{~m}$, and with 9 levels in the lower $1000 \mathrm{~m}$. A summary of the horizontal and vertical grid parameters is provided in Table 1. This configuration was selected as the best compromise for resolving the mesoscale circulations in the Valencia Region within a time frame regarded as useful for the model forecast within the computational resources available. Our version of RAMS includes the Mellor and Yamada (1982) level 2.5 turbulence parameterization, a full-column two-stream singleband radiation scheme that accounts for clouds to calculate short-wave and long-wave radiation (Chen and Cotton, 1983), and a Kuo-modified parameterization of sub-grid scale convection processes in the coarse domain (Molinari, 1985), whereas grids 2 and 3 utilize explicit convection only. The choice of this convective scheme is based on previous studies carried out within the area of study and for the summer season (Palau et al., 2005; PérezLanda et al., 2007). The cloud and precipitation microphysics scheme from Walko et al. (1995) was applied in all the domains. The LEAF-2 soil-vegetation surface scheme was used to calculate sensible and latent heat fluxes exchanged with the atmosphere, using prognostic equations for soil moisture and temperature (Walko et al., 2000).

Atmospheric boundary and initial conditions are derived from the operational global model of the National Centre for Environmental Prediction (NCEP) Global Forecasting System (GFS), at $6 \mathrm{~h}$ intervals and 1 x 1 degree resolution globally. Five variables including the temperature, relative humidity, zonal and meridional wind components and geopotential height for 26 vertical standard pressure levels are used in the initialization. Besides, a Four-Dimensional Data Assimilation (FDDA) technique is used to define the 
forcing at the lateral boundaries of the outermost five grid cells of the largest domain. The duration of the forecasts is three complete days (today, tomorrow and the day after tomorrow), initialized twice daily at 0000 and 1200 UTC using the GFS forecast grid from its forecast cycle 12-h earlier (Fig. 3). Finally, RAMS forecast output is available once per hour for display and analysis purposes.

In this kind of systems, operational time constraint is a key factor (Fast et al., 1995; Case et al., 2002). Thus, the real-time configuration of RAMS selected permits obtaining a good representation of the mesoscale circulations covering the whole Valencia Region in a computational time for which the model forecast is still useful. In this sense, if the forecast is based on 00 UTC GFS data, it will not be released until about 13 UTC, thus making it difficult to take immediate advantage of the results. That is, due to this delay in the forecast release, the results may not be applied to forecast a hazard situation for the first simulation day. On the other hand, if the RAMS forecast is based on the 12 UTC GFS data from the previous day of the forecast, it will be released with the current configuration at about 01 UTC of the current day, and thus be useful for forecasting risk situations with plenty of advance time.

\section{Description of the evaluation process.}

To evaluate the RAMS maximum and minimum temperatures, we have used data from both the CEAM meteorological station network and the IVIA agro-climatic station network. Using both measurement networks assures good coverage within the Valencia Region (IVIA, 2003; Estrela et al., 2007; Estrela et al., 2008; Gómez et al., 2009a; Gómez et al., 2009b; Gómez et al., 2010). IVIA daily maximum and minimum observed temperatures are open and freely available within the IVIA database (IVIA, 2003). The data used in this study is quality controlled by CEAM and IVIA (Corell-Custardoy et al., 2010; 
IVIA, 2003). Furthermore, we have performed an additional evaluation of both datasets. Firstly, we have taken advantage of both weather station networks to compare the daily maximum and minimum temperature values for those stations located close to each other but linked with each independent network (Fig. 2). Secondly, we have compared these magnitudes for stations located in specific thermo-climatic areas in which the Valencia Region has been divided (Miró et al., 2006; Estrela et al., 2007; Estrela et al., 2008). Measurements are quality controlled to reject data that show gross differences with nearby stations (Federico, 2011).

To analyse the RAMS results, we have followed a procedure that uses the simulated results obtained with the higher resolution domain to account for the terrain influence on the atmospheric flows (Salvador et al., 1999). This domain includes the best detailed description of the orography in the area of study available for each simulation. We have developed a tool to extract the RAMS-computed near-surface temperature forecast from CEAM and IVIA weather station data, by means of the RAMS/HYPACT Evaluation and Visualization Utilities (REVU) software (Tremback et al., 2002) applied to Grid 3. This magnitude is used for the comparison between the model and the observations. Specifying the latitude, longitude and sensor height for each observational location, REVU uses the GRAB option to extract data from the analysis files and to interpolate forecast data in three dimensions from surrounding RAMS grid points (Case et al., 2002), using an overlappingquadratic interpolation scheme in the horizontal direction. Additionally, REVU takes into account the orography as resolved by the model to compute the temperature for the specific location by means of a weighted linear interpolation corresponding to the two lowest levels in the simulation. This technique to extract RAMS-forecast data has already been used by Pastor et al. (2010) and Gómez et al. (2011) for precipitation. In each RAMS forecast cycle 
(0000 and 1200 UTC), the hourly RAMS temperatures forecasted for each of the CEAM and IVIA station locations are used to calculate the maximum and minimum temperatures for the corresponding station and for the three-days forecast period. The maximum and minimum temperatures of all the stations are stored for today, tomorrow and the day after tomorrow and for each RAMS operational cycle.

Two processes are carried out in the RAMS evaluation. The first process focuses on the scatter plots of measurements and the corresponding modelling magnitudes, which are plotted for visual comparison. Besides, a second process is based on statistical calculations (Willmott, 1981; Pielke, 2002; Palau et al. 2005; Pérez-Landa et al., 2007; Bartzokas et al., 2010; Federico, 2011), such as mean bias, root mean square error (RMSE), index of agreement (IoA), correlation coefficient (CORR), standard deviation of the difference (SD) and the anomaly correlation coefficient (ACC) for the maximum and minimum air temperature at $1.5 \mathrm{~m}$ above ground level ( $\mathrm{m}$ a.g.l.), as defined by the following equations:

$$
\text { Bias }=\frac{1}{N} \sum_{i=1}^{N}(F-O)
$$

$$
R M S E=\sqrt{\frac{1}{N} \sum_{i=1}^{N}(F-O)^{2}}
$$

$$
I o A=1-\frac{N(R M S E)^{2}}{\sum_{i=1}^{N}(|F-\bar{O}|+\mid O-\bar{O}}
$$




$$
\operatorname{CORR}=\frac{\sum_{i=1}^{N}[(O-\bar{O}) \cdot(F-}{\sqrt{\sum_{i=1}^{N}(O-\bar{l})^{2} \cdot \sum_{i=1}^{N}(F-}}
$$

$$
S D=\sqrt{\frac{1}{N} \sum_{i=1}^{N}(D-\bar{D})^{2}}
$$

$$
A C C=\frac{\sum_{i=1}^{N}[(O-\bar{O}) \cdot(F-\bar{C}}{\sqrt{\sum_{i=1}^{N}(O-\bar{O})^{2} \cdot \sum_{i=1}^{N}(F--}}
$$

where $N$ represents the number of observations included in the calculation. $F$ represents the simulated value and $O$ the observation, while $\bar{F}$ and $\bar{O}$ correspond to the time average forecast and observed respectively. Finally, $D$ corresponds to the difference $F-O$ and $\bar{D}$ to the average of this difference.

These two processes have been applied to the data from the different stations separately for evaluating the differences detected between them so as to carry out a more detailed analysis.

To study the skill of the RAMS model in forecasting the maximum and minimum temperatures by means of the above-mentioned processes, we have broken up the temperatures stored as much as possible. Thus, instead of merging all the simulation results obtained, for each station we have separated the maximum and minimum temperatures 
forecasted by RAMS within each forecast day and each forecast cycle. With the computational resources used to carry out this study, a high-resolution simulation takes about 6 hours to finish. And even if the available computational resources permitted the simulation time to be reduced, the restriction in the availability of data to initialize the model would still delay the forecast release. It follows that, even if better computational resources are available, the configuration of the model can always be improved, i.e., by increasing the horizontal resolution, number of points, etc. In this case, again, more resources are needed to finish the simulation on time. Thus, we decided to implement two daily RAMS runs: a first forecast that can provide an early warning of temperature spikes, and an update forecast that follows the evolution of the situation with recent data. To analyse the skill of the model in both forecast releases and to assure that the GFS forecast cycle does not significantly affect the RAMS results, 00 UTC and 12 UTC RAMS forecast cycles are analysed separately. This will show if the RAMS initialization method used is reasonably applicable. In relation to the forecast day, our aim is to study the stability of the model and the quality of the forecast results for the three simulation days. Thus, we will analyse how far in advance RAMS is able to forecast the observed maximum and minimum temperatures. RAMS model has been run from 1 June to 31 August for the 2007, 2008, 2009 and 2010 summer season. We have analysed the behaviour of the model in the two daily cycles and the three simulation days of these four years. To clarify the analysis of results, we only present those obtained merging all summer periods. However, it has been observed that the results are very similar evaluating each year separately (not shown), reflecting the model patterns in forecasting maximum and minimum temperatures within the summer season. Finally, in the next section we present both the results found for both the 00 and 12 UTC RAMS forecast cycles. The first is the one basically used to elaborate 
the high temperature hazard maps and activate the protocols established by the General Direction of Public Health of the Regional Government of Valencia. Nevertheless, results for the 12 UTC RAMS forecast cycle are also presented to show that both forecast cycles yield very similar results.

Additionally, in order to investigate the representative errors of the surface stations, we have used the procedure suggested by Myrick and Horel (2006) and Federico (2011). This method is based on the observation $\left(\sigma_{o}^{2}\right)$ and background $\left(\sigma_{b}^{2}\right)$ error covariances, where the background field is the RAMS first-day forecast for the 0000 UTC simulation, computed as previously described. The covariance between observational innovations (difference between observation and background values) at two points is computed as a function of the distance $r$ from all background field-observation pairs during all summer seasons:

$$
\operatorname{cov}(r)=\overline{\left(o_{1}-b_{1}\right)\left(o_{2}-b_{2}\right)}
$$

where $o$ is the measurement and $b$ is the background field interpolated at the station point. If we assume that: (a) the observational errors are uncorrelated with one another; and (b) the background and the observational errors are uncorrelated, Eq. (7) becomes:

$$
\operatorname{cov}(r=0)=\sigma_{o}^{2}+\sigma_{b}^{2}
$$

and

$$
\operatorname{cov}(r \neq 0)=\sigma_{b}^{2} \rho(r)
$$

where $\rho(\mathrm{r})$ is the background error correlation, which is assumed as an isotropic function of the distance. 
We have represented the covariance of observational innovations as a function of distance $r$ for all summer seasons and for maximum and minimum temperatures (Fig. 4). It is observed that the maximum temperature covariance drops sharply as a function of horizontal distance and remains almost constant for greater distances. However, a rather smoother covariance rate is found for the minimum temperature. For this parameter, a low variation is produced compared to that detected for the maximum. None of this curves asymptotes to 0 , which suggests that the RAMS background fields exhibit errors that remain correlated over distances of hundreds of kilometers, particularly in the case of the minimum temperatures. Fitting a least squares curve to the innovation covariance values for horizontal distances greater than $10 \mathrm{~km}$ and extrapolating the curve back to $r=0$ makes it possible to estimate the $\left(\sigma_{b}^{2}\right)$. A 6 th-order polynomial has been chosen to fit the covariance values at $r=0$, because it minimizes the $\chi^{2}$ of the interpolating polynomial (Federico, 2011). As a result, $\sigma_{b}^{2}$ for the maximum (minimum) temperature is estimated to be equal to $5.70{ }^{\circ} \mathrm{C}^{2}\left(8.02{ }^{\circ} \mathrm{C}^{2}\right)$. Using Eq. 8 , the observation error covariance can then be estimated from the difference between the innovation covariance value at distance zero and the estimate of $\sigma_{b}^{2}$. Thus, $\sigma_{o}^{2}$ for maximum (minimum) temperature is estimated to be equal to $0.90{ }^{\circ} \mathrm{C}^{2}\left(2.68{ }^{\circ} \mathrm{C}^{2}\right)$. Based on these results, we may see that $\sigma_{o}^{2}$ is quite reduced in relation to $\sigma_{b}^{2}$. However, a significant difference is identified in the observational representative error between the two parameters analysed, with the minimum temperatures presenting the largest values. In this case, the innovation covariance does not display a relevant decrease at long distance when compared to the maximum, showing the influence of the RAMS forecast far from the corresponding station and reducing the 
representativeness of the minimum temperatures. As a result, it appears that this condition is likely to play a significant role in the overestimation of the RAMS errors for this parameter over complex orography, as shown in the next section.

\section{Results.}

Because of the topographic, climatic and physical diversity of the study area, we have carried out a detailed analysis based on separating the data available from the different CEAM and IVIA stations. This has allowed us to differentiate the coastal stations from the inland ones and see how the topography and other physical characteristics of the station location can affect the observation and how the model is able to capture these effects. Thus, we were interested in finding out if the model might follow a pattern that could be isolated. There are basically two ways to do this. The first is to merge the two types of data and study the results obtained with all the data from each type separately (Pérez-Landa et al., 2007). This permits working with two groups of data, and relating the results to all the data connected to a concrete type. The second way to carry out the study is to select some stations from the different areas and analyse each of them separately (Palau et al., 2005). The latter could show the skill of the model not only to reproduce the characteristics of the station location but also to detect relationships between different stations in different locations but with similar physical or climatic characteristics. We have adopted the second formula. In a previous step, the CEAM and IVIA scatter plots and statistics were calculated for the different meteorological magnitudes and all the stations within the study area. This permitted us to carry out a preliminary analysis of the different stations. Then we grouped each station according to similar physical and climatic characteristics (Miró et al., 2006) and evaluated them individually based on the scatter plots and statistical scores. This initial analysis showed that RAMS presents a clearly different behaviour for coastal stations than 
for inland stations when forecasting maximum and minimum temperatures. Moreover, precoastal stations behave like either coastal or inland stations according to topographic and physical issues. As a result of this finding, some representative stations within the study area have been selected to analyse and discuss the RAMS results in the current section (Fig. 5).

As we can see, for coastal stations (Fig. 6a, 6c, 6e), RAMS generally does a good job of reproducing the temperature cycle and magnitude for the whole period in the maximum as well as the minimum temperatures. It also captures quite well the observed maximum and minimum temperature peaks. However, with respect to the deviations between the modeled and measured maximum and minimum temperatures a different behaviour is observed. In the case of the maximum temperature, the model forecast has a clear tendency to underpredict the observations. On the other hand, the deviations in the minimum temperature forecasted by the model have a tendency to overpredict the observations. On coastal locations, the model seems to behave better for minimum temperatures than for maximum temperatures, as reflected in the better fit between simulated values and observed values. In forecasting both variables, RAMS shows very stable behaviour, as can be appreciated in the similar results obtained for the three days of simulation. In fact, for some stations and situations, RAMS provides better forecasts for the second and third day than for the first one (Fig. 6a, 6c, 6e).

RAMS-simulated maximum temperatures for inland stations agree quite well with the observed maximum, better than for coastal stations (Fig. 6b, 6d, 6f). In this case, the separation between forecast and measurement data is substantially reduced compared with that observed for coastal stations. Besides, these differences have a tendency to overpredict the measurement, thus reversing the tendency obtained for coastal stations. In the case of 
minimum temperatures for inland stations, the skill of the model decreases in general with respect to their forecast for coastal stations. For inland stations, the model tends to overpredict the minimum temperature forecast, as was also observed for coastal stations. Comparing both kinds of stations, the differences between forecasted and measured minimum temperatures for inland stations are greater than those obtained for coastal stations. This behaviour of the model is maintained for the three days of simulation (Fig. $6 b, 6 d, 6 f)$.

Finally, as can be seen in Fig. 7, the results obtained for the 12 UTC RAMS cycle are very similar to those released by the 00 UTC RAMS cycle.

To obtain more specific information on the global skill of the RAMS model for determining maximum and minimum temperatures within the Valencia Region, we have used different statistical indexes to carry out a quantitative analysis for each individual station in the CEAM and IVIA measurement networks. Tables 2 and 3 show the statistics for the maximum and minimum temperatures obtained for the representative coastal, precoastal and inland stations, on the first day of simulation for all forecasting period (summer 2007, 2008, 2009 and 2010).

Analysing the stations not far from the coast (pre-coastal) we have found that the behaviour of the model with respect to both maximum and minimum temperatures for these locations is generally related to the topographic complexity of the station location. Table 2 presents the maximum temperature statistics obtained for the stations selected. The RMSE values are an indication of how well the RAMS model is able to simulate this variable. In general, the values obtained are near $2{ }^{\circ} \mathrm{C}$. Similar results are found for the SD score, with the lowest ones corresponding to inland stations, as in the case of CAS station with a value of $1.58^{\circ} \mathrm{C}$. For coastal stations, the model has a low negative bias (below $2{ }^{\circ} \mathrm{C}$ ), with 
average values also showing an underestimation for all the coastal stations. In this case, the RAMS-simulated heating is lower than the observed heating. Besides, the ACC values, above 0.60 , indicate the usefulness of the model for the maximum temperature at the coast. For the inland station and the pre-coastal ones, the model has a slight positive bias, showing that RAMS is capturing very well the heating effects on the daytime temperature for these locations. Furthermore, the high ACC values, above 0.80, indicate that the model is able to capture very well the day-to-day variability for the maximum temperature inland. This statistical score also indicates the model skill for pre-coastal stations, with values closer to those observed at the coast or inland, depending on the station location. All the IoA values are near 0.9 , indicating that the daily and the day-to-day maximum temperature evolution is very well reproduced by the model. Moreover, CORR score has values near 0.9 , showing a very good relation between model-data maximum temperatures.

To procure a more detailed picture, maps of the bias and RMSE statistic scores has been drawn for maximum and minimum temperatures within the Valencia Region, using the available CEAM and IVIA data (34 stations operated by CEAM and 43 operated by IVIA; Fig. 1). The map for RMSE corresponding to the maximum temperatures is introduced in Fig. 8. In general, the RMSE for the whole territory remains around $2{ }^{\circ} \mathrm{C}$, with the exception of some areas. This can be due to the complexity of the area surrounding the station that produces the model not to capture the local characteristics properly. Besides, although the values for the three forecast days are close to the ones obtained for the first day, the RMSE shows a small increase with the forecasting time. In this sense, the area spanned for RMSE values higher than $2{ }^{\circ} \mathrm{C}$ within the third day of simulation is more extensive than that observed in the first day. These results are also reproduced in the 12 UTC RAMS cycle (Fig. 8b, 8d, 8f), with slightly better values of RMSE than the estimated 
within the 00 UTC cycle. In the case of the bias, we can see that the values for this score show an underestimation of the observations for coastal stations while an overestimation is reproduced by the model for maximum temperatures as we move inland (Fig. 9). There is a bias distribution associated with the complex terrain as well as with steep topography, which is a tendency reproduced by RAMS for the entire region of study.

Table 3 shows the statistics on minimum temperatures obtained merging data for all years. In this case, RMSE values obtained for the coastal and the pre-coastal stations located over areas of low topographical complexity are near $2{ }^{\circ} \mathrm{C}$. The values obtained for the inland and more inland pre-coastal stations (LLI), reveal a systematic error of the model, with values higher than $4{ }^{\circ} \mathrm{C}$. For the $\mathrm{SD}$, the lowest scores are reached over flatter terrain, with values lower than $2{ }^{\circ} \mathrm{C}$. This error can also be seen for the bias and average scores, which show a clear overestimation for nearly all stations. For inland as well as precoastal stations located in areas of high topographical complexity, bias values are near $3{ }^{\circ} \mathrm{C}$. In contrast, for all coastal stations and the pre-coastal stations located in a flatter terrain, the bias scores show values near or even lower than $1{ }^{\circ} \mathrm{C}$. The IoA for the minimum temperature is near 0.8 for the coastal stations. For inland stations, the IoA values are near 0.6. Thus, although the model reproduces the daily and day-to-day minimum temperature evolution quite well for coastal stations, it has more problems in this respect for inland stations. This result is also shown in the CORR score. Once again, for pre-coastal stations, the behaviour of the IoA and CORR statistics is similar to that described for the bias and RMSE scores. These results are also shown by the ACC score. In this case, the model is still able to capture the day-to-day variability for the minimum temperature at the coast, as indicated by the values of ACC, near 0.70 . However, this score shows the complexity in forecasting minimum temperatures inland. In this regard, the ACC value falls below 0.60. 
The results shown in tables 2 and 3 for the 00 UTC forecast are very similar to those obtained for the 12 UTC RAMS forecast update (not shown).

The RMSE for minimum temperatures increases slightly as we move forward in the simulation, although the values are close to the ones obtained for the first day of simulation (Fig. 10). This result is reproduced both by the 00 and 12 UTC RAMS cycles. However, it seems that using the 12 UTC simulations, RAMS produces slightly lower values of RMSE compared to those obtained using the 00 UTC cycle. As a difference with maximum temperatures, when modeling the minimum, higher errors are obtained. In this case, areas with RMSE score higher than $3{ }^{\circ} \mathrm{C}$ are more extensive than those estimated for the maximum temperatures. According to the bias results, significant differences between both daily temperatures are also reproduced by the model (Fig. 11). As a result, for minimum temperatures, the bias has a general tendency to overestimate the measured values with different degree of accuracy. Thus, reduced areas of negative bias are observed. Furthermore, the values of this statistics for the minimum are higher than those estimated for the maximum temperatures both in magnitude as well as regarding spatial area distribution. This effect of bias is reproduced for the complete Valencia Region, especially in those areas where the terrain complexity is evident.

In Estrela et al. (2008), it is explained the high-temperature prediction system for the Valencia Region based on the RAMS-forecast maximum and minimum temperatures. A different degree of agreement is found between the forecast and observed hazard-level for coastal and inland areas, higher in the coast. The current work explains these results due to the fact that the minimum temperatures are over-predicted by RAMS inland. This provokes a clear tendency to forecast higher hazard-levels over these areas compared to those observed. In contrast, when the maximum temperature plays the most significant role in 
determining the high-temperature hazard-level, the system is rather useful as little differences are found between the forecast and observed hazard-level. These results seem clear looking at Fig. 6 and Fig. 7. In this sense, it is also observed that for coastal stations, the distribution of both the maximum and minimum temperatures shows a skilled degree of correlation between the forecast and observed hazard-levels.

\section{Conclusions.}

The main aim of this work has been to evaluate the skill of the RAMS model in forecasting summertime maximum and minimum temperatures for the whole Valencia Region, to be used within the extreme-temperature forecast and warning system implemented in this area. For this, we have used the high-resolution configuration of RAMS running operationally at CEAM. We have focused on an evaluation of the model, using all the data available for the 2007, 2008, 2009 and 2010 summer periods from both inland and coastal stations. The results indicate that RAMS reproduces the maximum temperature cycles quite well and is also able to capture the high maximum temperature peaks that occurred in the summer season. In addition, the model can also capture the minimum temperature peaks produced in this period. However, RAMS has more difficulties in determining the minimum temperature, tending to overestimate the observations. Regarding the different station locations, we have found that RAMS behaviour with respect to both maximum and minimum temperatures differs between inland stations and coastal stations. In relation to the maximum, RAMS shows good agreement with the observations at both types of stations. However, the behaviour of the model is not the same as the tendency of the model. In this sense, RAMS tends to overpredict the observations at inland stations while underestimating the coastal ones. On the other hand, the forecasted minimum temperatures have a general tendency to over-predict 
the measurements at both kinds of stations. Although the model results for coastal locations agree quite well with the observations, higher errors are encountered for the most inland locations, where the topographical complexity is more marked. In relation to the minimum temperatures forecasted by the model for pre-coastal stations, RAMS follows the behaviour shown for the coastal stations or the inland stations depending on the topographical complexity of the measurement site.

The same results are found for the three days of simulation, indicating that RAMS maximum and minimum temperature forecasts are very stable for at least three forecast days. Moreover, the initialization method used for RAMS is valid as the results obtained are very similar in both daily simulation cycles. The influence of the temporal gap in the GFS data used to initiate the RAMS model in the operational implementation of this study is not critical in the results obtained. Thus, RAMS provides very useful information at least three days in advance and the daily update forecast basically follows the first daily forecast behaviour.

Accordingly, RAMS is able to reproduce maximum temperatures with a great degree of accuracy and thus could be perfectly applied to forecast maximum temperatures for the whole Valencia Region. Besides, RAMS is very useful for minimum temperature forecasting at coastal stations within the Valencia Region and it is also able to reproduce the minimum temperature peaks quite well over the whole Valencia Region. On the contrary, RAMS significantly overestimates the minimum temperature for inland areas for a considerable number of days within the summer period. This issue is probably related to the nocturnal cooling of the ground which is not satisfactorily simulated by the model, as has already been pointed out in diagnostic studies (Palau et al., 2005; Pérez-Landa et al., 2007). The same results have also been found for other Mediterranean Regions using other real- 
time mesoscale models (Bartzokas et al., 2010). Likewise, in other areas with Mediterranean-type climate regimes, it has been found that atmospheric humidity is the main cause of elevated minimum temperatures (Gershunov et al., 2009; Gershunov and Guirguis, 2012). Finally, the larger representativeness error for the minimum temperature using the current methodology could also be related to the overestimation of this parameter in complex orography.

It is the plan of the authors to continue verifying the CEAM RAMS real-time forecasting system by focusing on the skill of the model in forecasting other meteorological variables within the Valencia Region. More in-depth analysis will help to isolate the processes causing the main differences between RAMS-forecasted and observed maximum and minimum temperatures, with the aim of improving the system implemented. 
Acknowledgement. This work has been funded by the Spanish Ministerio de Educación y Ciencia through the projects CGL2008-04550 (Proyecto NIEVA), CSD2007-00067 CONSOLIDER-INGENIO 2010 (Proyecto GRACCIE) and CGL2007-65774/CLI (Proyecto MAPSAT), and by the Regional Government of Valencia through the contract "Simulación de las olas de calor e invasiones de frío y su regionalización en la Comunitat Valenciana" ("Heat wave and cold invasion simulation and their regionalization at the Valencia Region") and the project PROMETEO/2009/086. The authors wish to thank F. Pastor, J. Miró and M. J. Barberà for their appreciable collaboration as well as J. L. Palau and R. Niclòs for their constructive comments while writing this paper. We also want to thank Jackie Scheiding for the review of the English text. NCEP are acknowledged for providing the GFS meteorological forecasts for RAMS initialization. 


\section{References}

Bartzokas A, Kotroni V, Lagouvardos K, Lolis CJ, Gkikas A, Tsirogianni MI (2010). Weather forecast in north-western greece: Riskmed warnings and verification of mm5 model. Natural Hazards and Earth System Sciences 10:383-394.

Case JL Manobianco J, Dianic AV, Wheeler MM, Harms DE, Parks CR (2002). Verification of high-resolution rams forecasts over east-central Florida during the 1999 and 2000 summer months. Weather and Forecasting 17:1133-1151.

Chen C, Cotton WR (1983). A one-dimensional simulation of the stratocumulus-capped mixed layer. Boundary-Layer Meteorology 25:289-321.

Cotton WR, Pielke RAS, Walko RL, Liston GE, Tremback CJ, Jiang H, McAnelly RL, Harrington JY, Nicholls ME, Carrio GG, McFadden JP (2003). RAMS 2001: Current status and future directions. Meteorology and Atmospheric Physics 82 (1-4):5-29.

Corell-Custardoy D, Valiente-Pardo JA, Estrela-Navarro MJ, García-Sánchez F, AzorínMolina C (2010). Red de torres meteorológicas de la Fundación CEAM (CEAM meteorological station network), in: 2nd Meeting on Meteorology and Climatology of the Western Mediterranean, Valencia, Spain.

Dudhia J (1993). A non-hydrostatic version of the Penn State/NCAR mesoscale model: validation tests and simulation of an Atlantic cyclone and cold front, Mon. Weather Rev., 121, $1493-1513$.

Estrela M, Pastor F, Miró J, Gómez I, Barberà M (2007). Heat waves prediction system in a mediterranean area (valencia region). 7th EMS Annual Meeting / 8th European Conference on Applications of Meteorology. 
Estrela M, Pastor F, Miró J, Gómez I, Barberà M (2008): Diseño de un sistema de predicción de niveles de riesgo por temperaturas extremas para la Comunidad Valenciana. Olas de calor, 235-252. Riesgos Climáticos y Cambio Global, Colección Interciencias.

Fast JD (1995). Mesoscale modeling in areas of highly complex terrain employing a fourdimensional data assimilation technique. Journal of Applied Meteorology 34:2762-2782.

Federico S (2011). Verification of surface minimum, mean, and maximum temperature forecasts in Calabria for summer 2008. Natural Hazards and Earth System Sciences 11: 487-500.

Gershunov A, Cayan D, Iacobellis S (2009). The great 2006 heat wave over California and Nevada: Signal of an increasing trend. Journal of Climate 22: 6181-6203.

Gershunov A, Guirguis K (2012). California heat waves in the present and future. Geophysical Research Letters 39, L18710, doi:10.1029/2012GL052979.

Gómez I, Pastor F, Estrela MJ, Miró J, Barberà MJ (2007). Development of a Java-based graphical user interface to control/monitor a real-time forecast and alert system. 7th EMS Annual Meeting/ 8th European Conference on Applications of Meteorology, San Lorenzo de El Escorial, Spain.

Gómez I, Estrela M (2009a). Operational forecasting of daily temperatures in the valencia region. Part I: maximum temperatures in summer. 9th EMS Annual Meeting/9th European Conference on Applications of Meteorology, Toulouse, France.

Gómez I , Estrela M (2009b). Operational forecasting of daily temperatures in the valencia region. Part II: minimum temperatures in winter. 9th EMS Annual Meeting/9th European Conference on Applications of Meteorology, Toulouse, France. 
Gómez I, Estrela MJ (2010). Design and development of a java-based graphical user interface to monitor/control a meteorological real-time forecasting system. Computers \& Geosciences 36:1345-1354. doi:10.1016/j.cageo.2010.05.005.

Gómez I, Pastor F, Estrela MJ (2011). Sensitivity of a mesoscale model to different convective parameterization schemes in a heavy rain event. Natural Hazards and Earth System Sciences 11: 343-357, doi: 10.5194/nhess-11-343-2011.

Gómez I, Marin MJ, Pastor F, Estrela MJ (2012). Improvement of the Valencia region ultravioleta index (UVI) forecasting system. Computers \& Geosciences 41: 72-82, doi: 10.1016/j.cageo.2011.08.015.

Gómez-Tejedor JA, Estrela MJ, Millán MM (1999). A mesoscale model application to fire weather winds. International Journal of Wildland Fire 9:255-263.

IVIA (2003): IVIA (instituto valenciano de investigaciones agrarias): Servicio de tecnología del riego. SIAR (servicio integral de asesoramiento al regante) red de estaciones agroclimáticas de la Comunitat Valenciana. Tech. rep. URL http://estaciones.ivia.es/estacion. Mellor G, Yamada T (1982). Development of a turbulence closure model for geophysical fluid problems. Reviews of Geophysics and Space Physics 20:851-875.

Miró JJ, Estrela MJ, Millán MM (2006). Summer temperature trends in a mediterranean area (valencia region). International Journal of Climatology 26:1051-1073.

Molinari J. (1985). A general form of kuo's cumulus parameterization. Monthly Weather Review 113:1411-1416.

Myrick DT, Horel JH (2006). Verification of surface temperature from the National Digital Forecast Database over the western United States, Weather and Forecasting, 21:869-

892. 
Palau JL, Pérez-Landa G, Diéguez JJ, Monter C, Millán MM (2005). The importance of meteorological scales to forecast air pollution scenarios on coastal complex terrain. Atmospheric Chemistry and Physics 5:2771-2785.

Pastor F, Estrela MJ, Peñarrocha D, Millán MM (2001). Torrential rains on the spanish mediterranean coast. Modeling the effects of the sea surface temperature. Journal of Applied Meteorology 40(7):1180-1195.

Pastor F, Gómez I, Estrela MJ (2010). Numerical study of the october 2007 flash flood in the Valencia region (Eastern Spain): the role of orography. Natural Hazards and Earth System Sciences 10:1331-1345. doi:10.5194/nhess-10-1331-2010.

Pérez-Landa G, Ciais P, Sanz MJ, Gioli B, Miglietta F, Palau JL, Gangoiti G, Millán M (2007). Mesoscale circulations over complex terrain in the Valencia coastal region, Spain. Part 1: Simulation of diurnal circulation regimes. Atmospheric Chemistry and Physics 7:1835-1849.

Pielke Sr. RA (2002). Mesoscale meteorological modeling. 2nd Edition. Academic Press, San Diego, CA, 676 pp.

Salvador R, Calbó J, Millán M (1999). Horizontal grid size selection and its influence on mesoscale model simulations. Journal of Applied Meteorology 39(9):1311-1329. Salvador R, Millán M, Mantilla E, Baldasano JM. 1997. Mesoscale modelling of atmospheric processes over the western mediterranean area during summer. International Journal of Environment and Pollution 8:513-529.

Tremback CJ, Walko RL, Bell MJ (2002). RAMS/HYPACT Evaluation and Visualization Utilities (REVU) user's guide, version 2.3.1, Technical Report.

Walko RL, Cotton WR, Meyers MP, Harrington JY (1995). New RAMS cloud microphysics parameterization. Part I: The single-moment scheme. Atmospheric Research 38:29-62. 
Walko RL, Band LE, Baron J, Kittel TGF, Lammers R, Lee TJ, Ojima D, Pielke RA, Taylor C, Tague C, Tremback CJ, Vidale PL (2000). Coupled atmospheric-biophysics-hydrology models for environmental modeling. Journal of Applied Meteorology 39:931-944. Willmott CJ (1981). On the validation of models. Physical Geography 2 (2):184-194. 


\section{Figure Captions.}

Fig. 1. Location (a) and orography (b) of the Valencia Region.

Fig. 2. RAMS model domain configuration and distribution of the CEAM and IVIA stations. A total of 34 CEAM (triangle) and a total of 43 IVIA (square) stations have been used in the analysis.

Fig. 3. CEAM RAMS real-time implementation.

Fig. 4. Binned innovation covariance for maximum (red) and minimum (blue) temperatures. The solid curves are 6th order polynomial fittings of the binned covariances and the corresponding parameter.

Fig. 5. Representative coastal (triangle), pre-coastal (square) and inland (cross) CEAM and IVIA stations and orography of domain $3(\mathrm{~m})$.

Fig. 6. Simulated versus measured maximum (red) and minimum temperatures (blue), for the 1 June to 30 August in VIL (coastal station) (on the left; a, first; c, second; e, third day of simulation) and CAM (inland station) (on the right; $b$, first; $d$, second; $f$, third day of simulation) for the 00 UTC RAMS cycle 2007, 2008, 2009 and 2010 summer season.

Fig. 7. As in Fig. 6, but for the 12 UTC RAMS cycle 2007, 2008, 2009 and 2010 summer season.

Fig. 8. RMSE score for maximum temperatures merging all station data from CEAM and IVIA networks. 00 UTC RAMS cycle (on the left; a, first; c, second; e, third day of simulation) and 12 UTC RAMS cycle (on the right; b, first; $d$, second; f, third day of simulation).

Fig. 9. BIAS score for maximum temperatures merging all station data from CEAM and IVIA networks. 00 UTC RAMS cycle (on the left; a, first; c, second; e, third day of 
simulation) and 12 UTC RAMS cycle (on the right; b, first; $d$, second; f, third day of simulation).

Fig 10. As in Fig. 8, but for minimum temperatures.

Fig 11. As in Fig. 9, but for minimum temperatures. 
Tables.

Tabla 1. Rams model settings for the three simulation grids: number of grid points in the $\mathrm{x}$, $\mathrm{y}$ and $\mathrm{z}$ directions ( $\mathrm{xx}$, ny and $\mathrm{nz}$ ), horizontal grid spacing (dx) and timestep (t).

\begin{tabular}{cccccc}
\hline Gris & nx & ny & nz & dx $(\mathrm{m})$ & $\mathrm{t}(\mathrm{s})$ \\
\hline 1 & 83 & 58 & 24 & 48000 & 60 \\
2 & 146 & 94 & 24 & 12000 & 30 \\
3 & 78 & 126 & 24 & 3000 & 10 \\
\hline
\end{tabular}

Tabla 2. Maximum temperature statistics for summer 2007, 2008, 2009 and 2010, divided by station location for the first day of simulation within the 00 UTC RAMS cycle.

\begin{tabular}{lcccccc}
\hline Station & Bias & RMSE & SD & CORR & IoA & ACC \\
\hline \multicolumn{7}{c}{ Coastal Stations } \\
BEN & -1.43 & 2.26 & 1.75 & 0.75 & 0.80 & 0.65 \\
TAV & 0.09 & 2.30 & 2.30 & 0.79 & 0.87 & 0.79 \\
PIL & -2.15 & 2.98 & 2.06 & 0.78 & 0.78 & 0.65 \\
\hline \multicolumn{7}{c}{ Inland Stations } \\
\hline CAS & 1.14 & 1.95 & 1.58 & 0.91 & 0.93 & 0.87 \\
VIS & 2.31 & 2.95 & 1.84 & 0.89 & 0.86 & 0.75 \\
REQ & 1.50 & 2.65 & 2.18 & 0.87 & 0.90 & 0.82 \\
\hline \multicolumn{7}{c}{ Pre-coastal Stations } \\
\hline SAN & 0.76 & 2.04 & 1.90 & 0.77 & 0.86 & 0.75 \\
LLI & 0.32 & 2.06 & 2.04 & 0.83 & 0.90 & 0.83 \\
ORI & 0.68 & 2.16 & 2.05 & 0.84 & 0.90 & 0.83 \\
\hline
\end{tabular}

Tabla 3. Minimum temperature statistics for summer 2007, 2008, 2009 and 2010, divided by station location for the first day of simulation within the 00 UTC RAMS cycle.

\begin{tabular}{lcccccc}
\hline Station & Bias & RMSE & SD & CORR & I. A. & ACC \\
\hline \multicolumn{7}{c}{ Coastal Stations } \\
\hline BEN & 0.16 & 1.85 & 1.85 & 0.77 & 0.87 & 0.76 \\
TAV & 1.34 & 2.16 & 1.70 & 0.76 & 0.81 & 0.66 \\
PIL & -0.42 & 1.75 & 1.70 & 0.69 & 0.82 & 0.67 \\
\hline \multicolumn{7}{c}{ Inland Stations } \\
\hline CAS & 3.91 & 4.73 & 2.66 & 0.62 & 0.55 & 0.40 \\
VIS & 3.64 & 4.39 & 2.44 & 0.67 & 0.60 & 0.44 \\
REQ & 3.86 & 4.53 & 2.35 & 0.74 & 0.58 & 0.50 \\
\hline \multicolumn{7}{c}{ Pre-coastal Stations } \\
\hline SAN & 0.89 & 2.32 & 2.14 & 0.74 & 0.81 & 0.71 \\
LLI & 3.27 & 4.26 & 2.74 & 0.62 & 0.62 & 0.45 \\
ORI & 1.39 & 2.48 & 2.05 & 0.64 & 0.73 & 0.56 \\
\hline
\end{tabular}



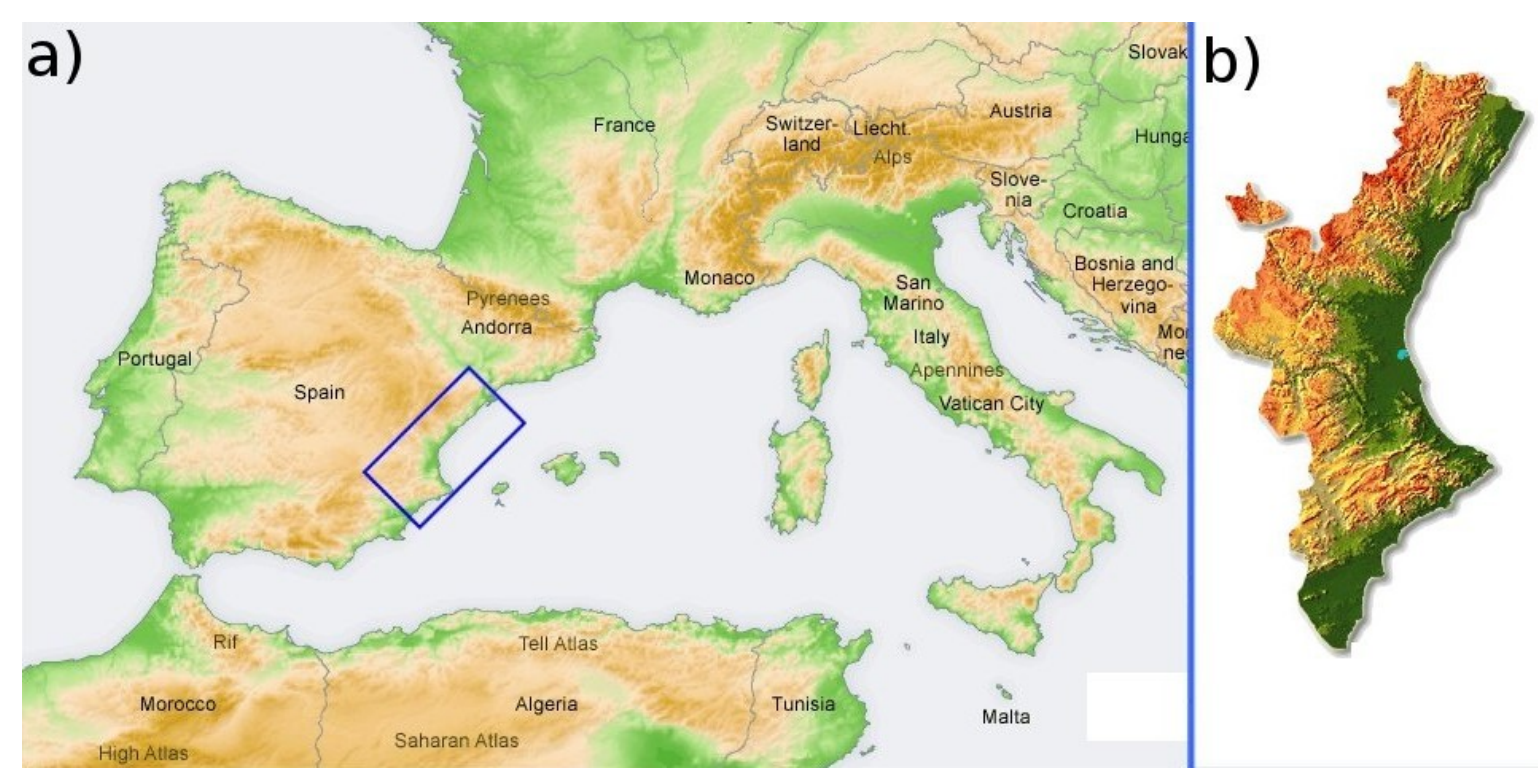

Figure 1

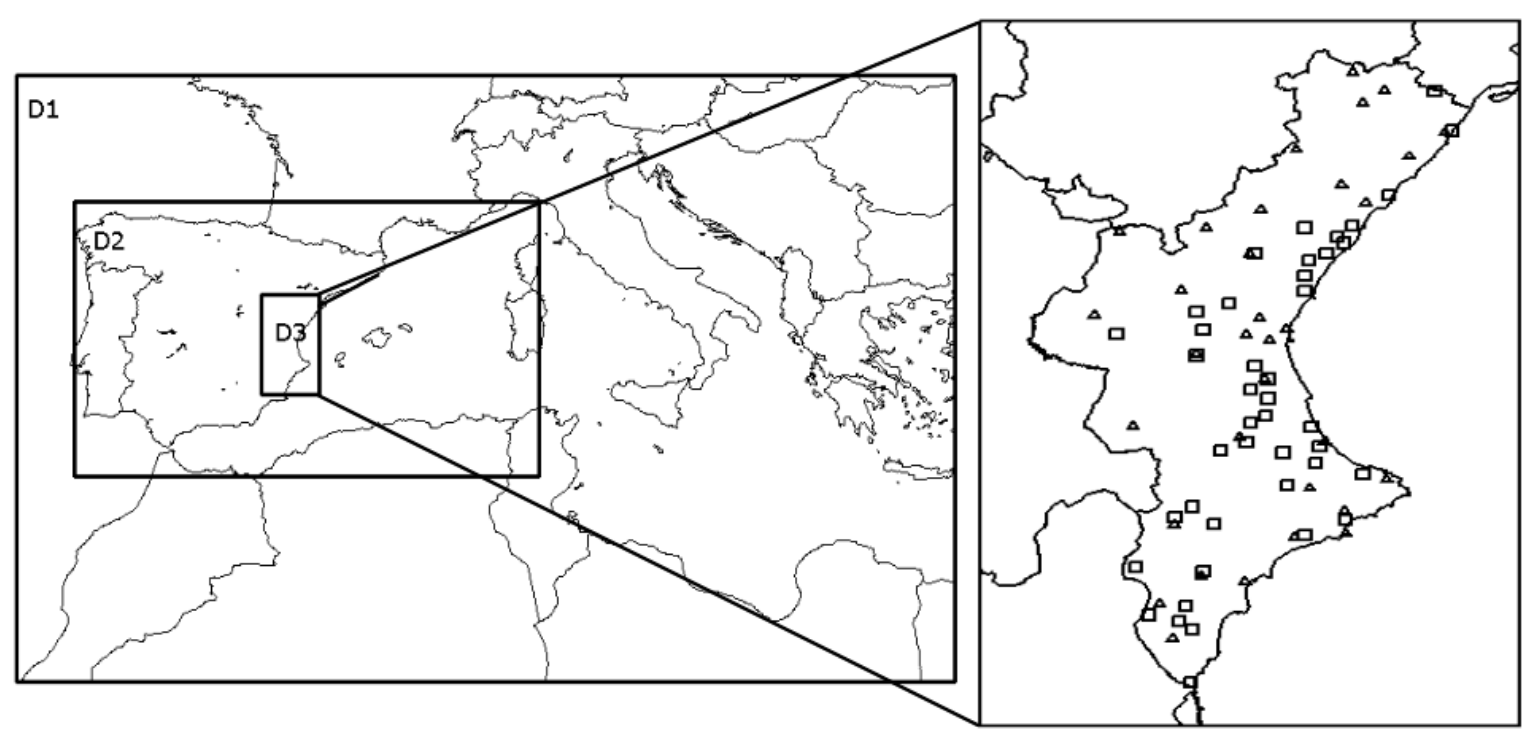

Figure 2 


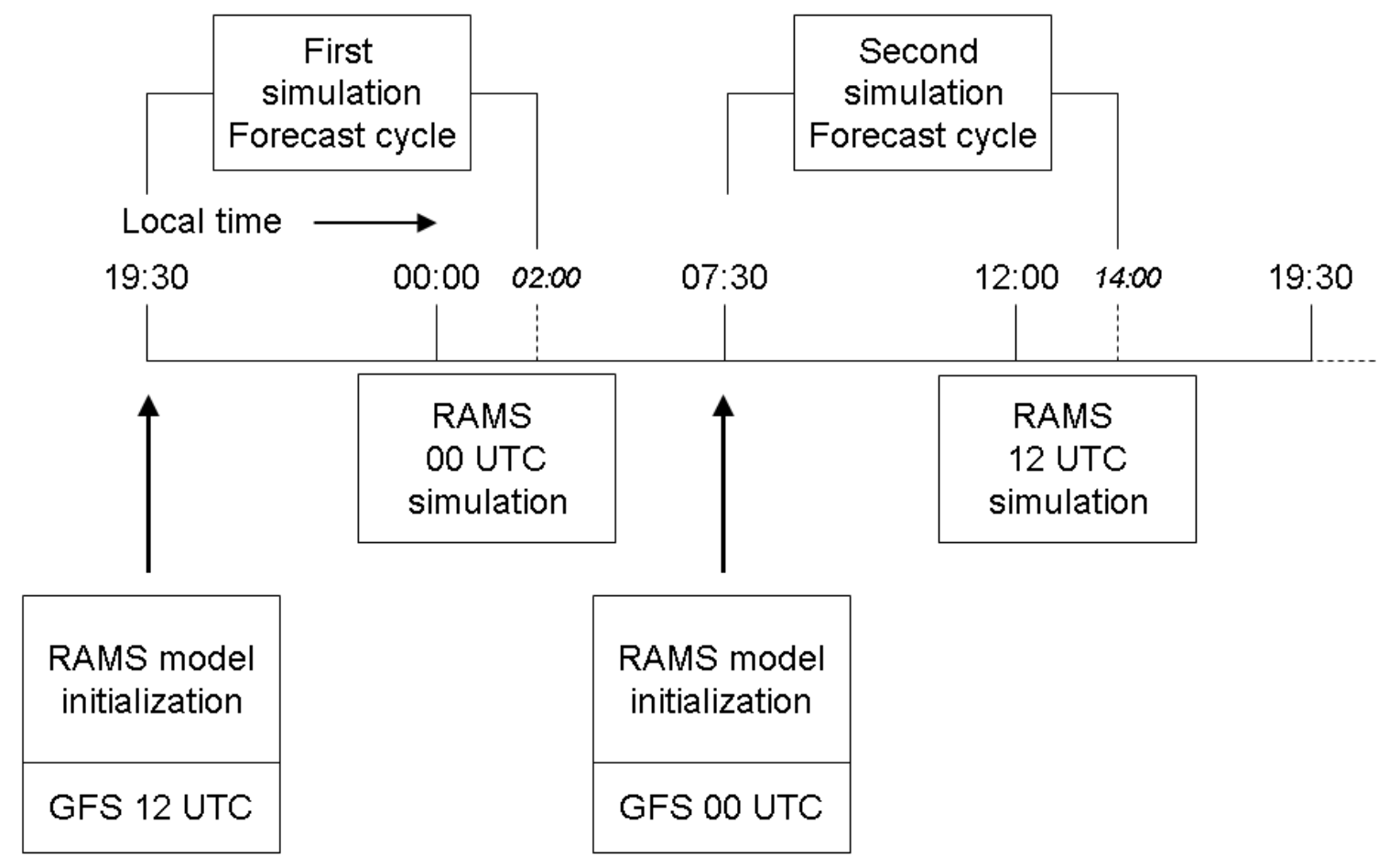

Figure 3 


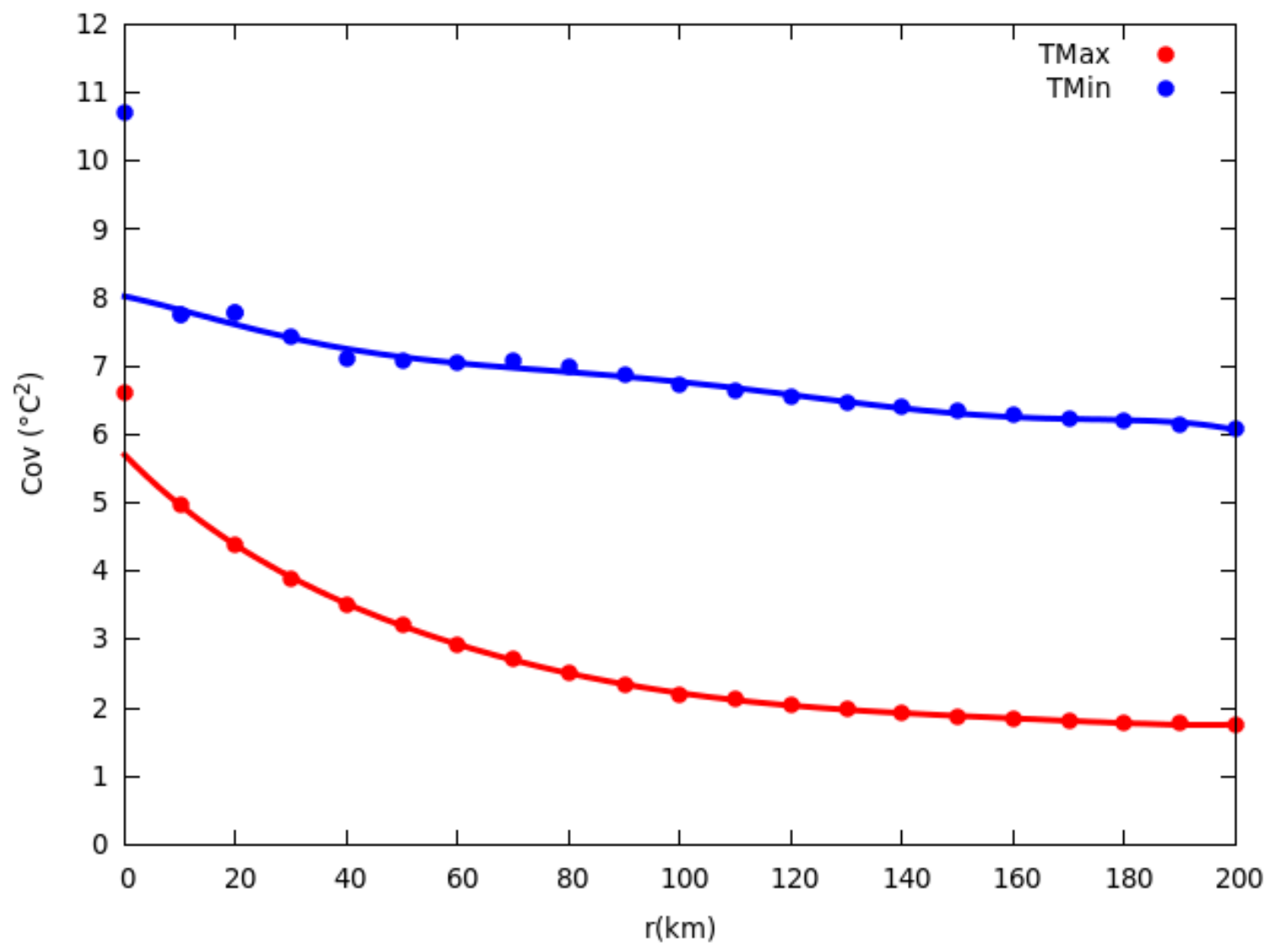

Figure 4 

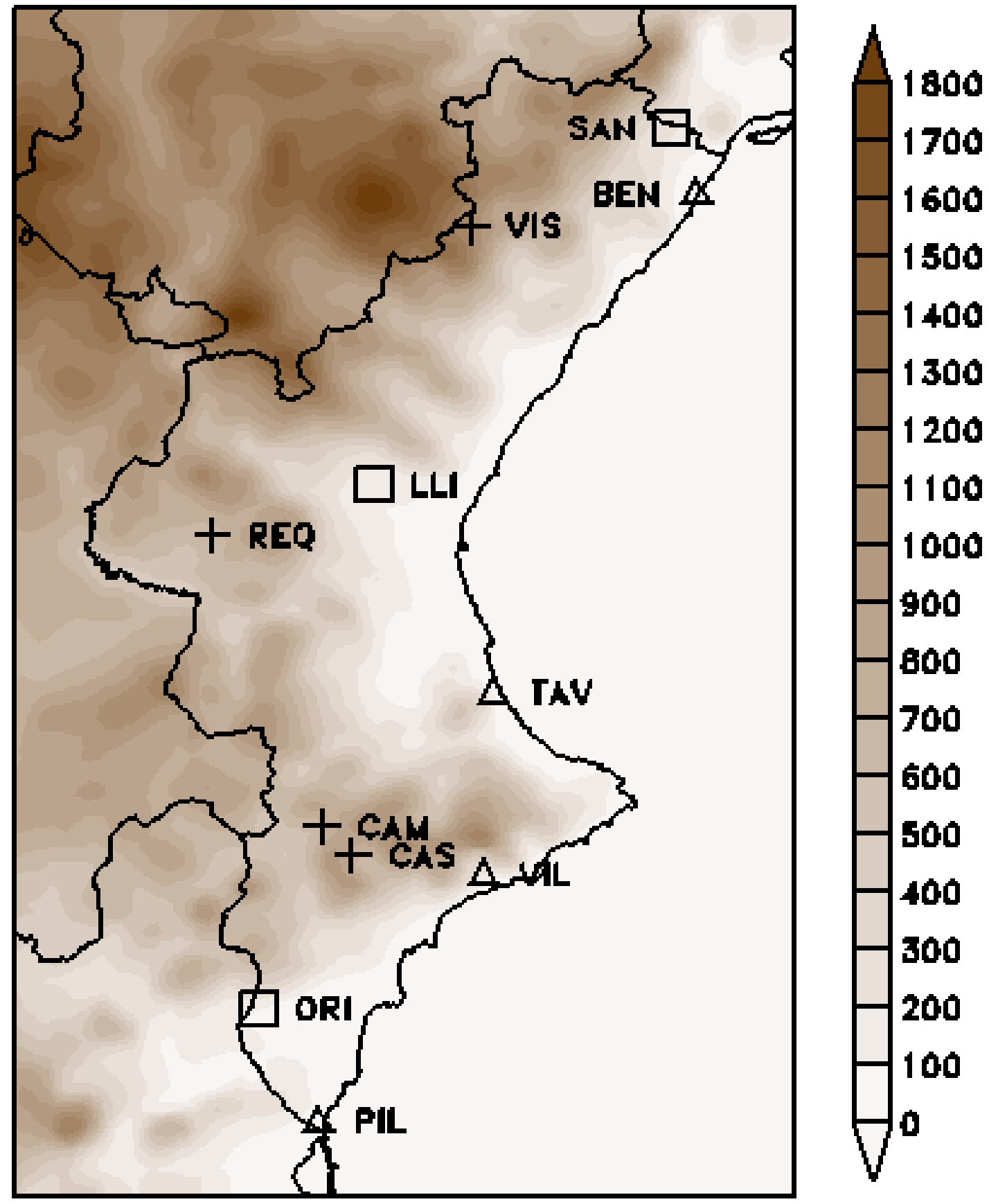

Figure 5 
(a)

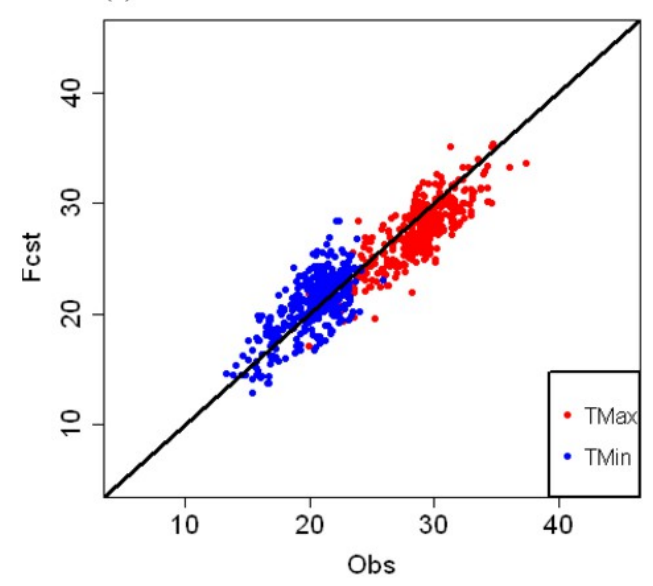

(c)

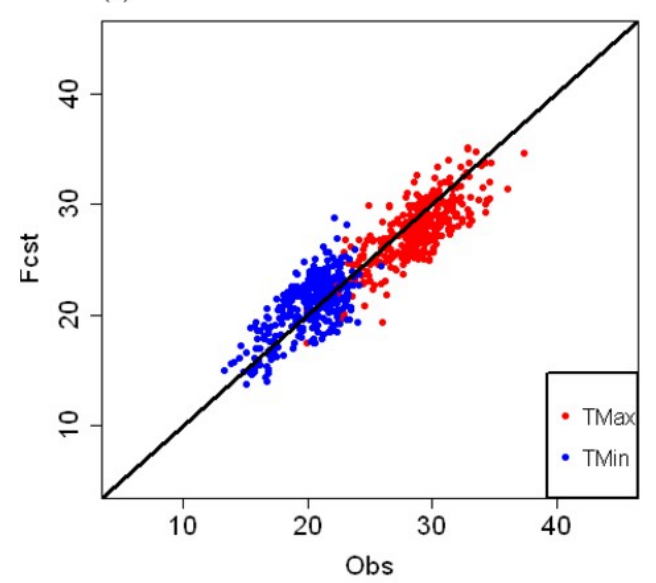

(e)

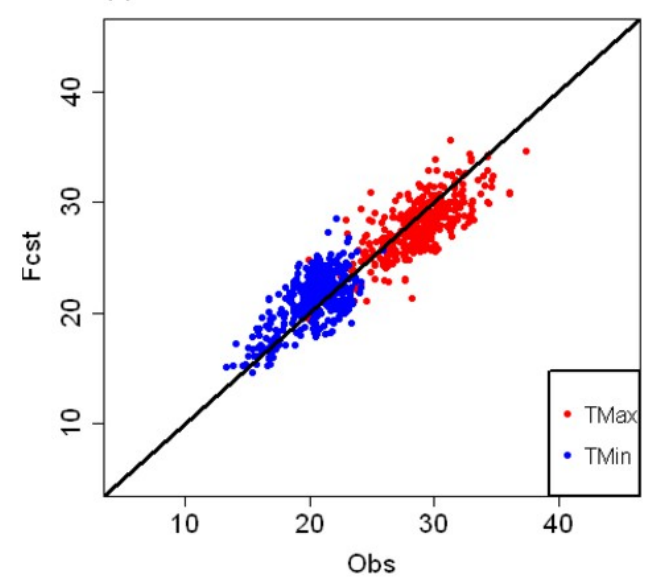

(b)

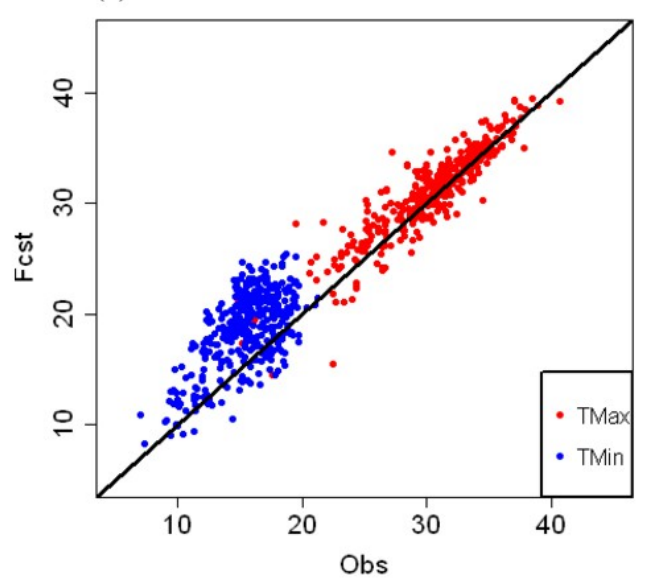

(d)
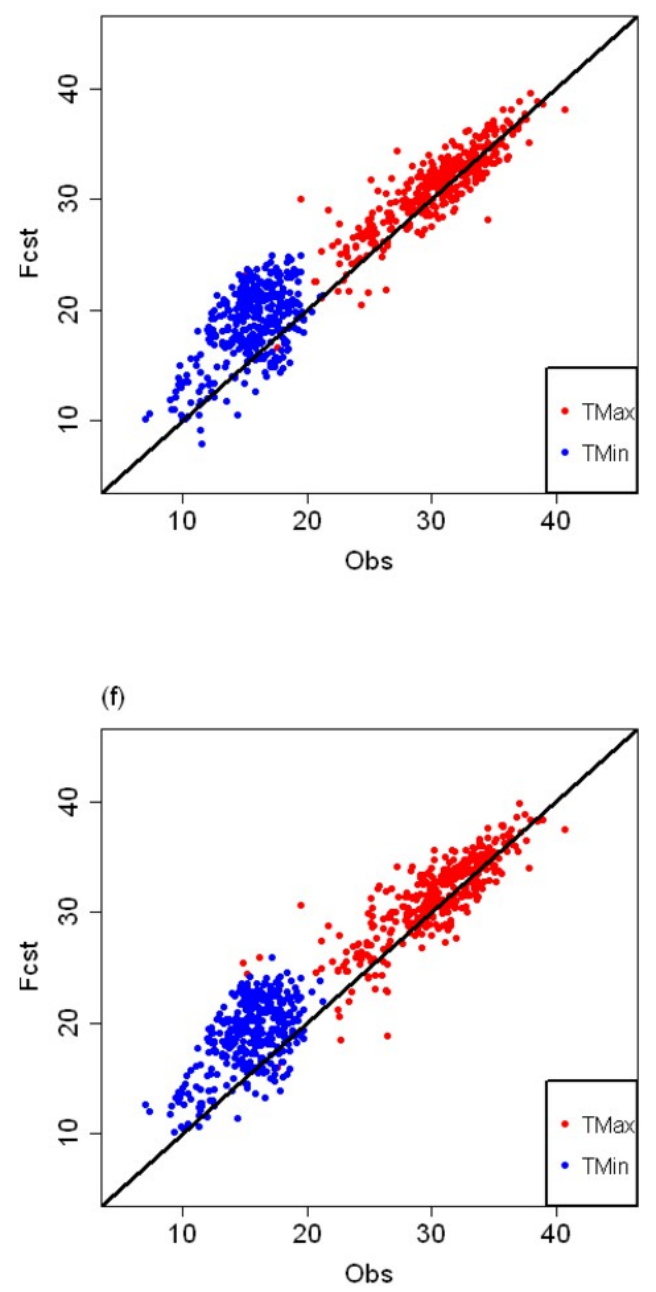

Figure 6 

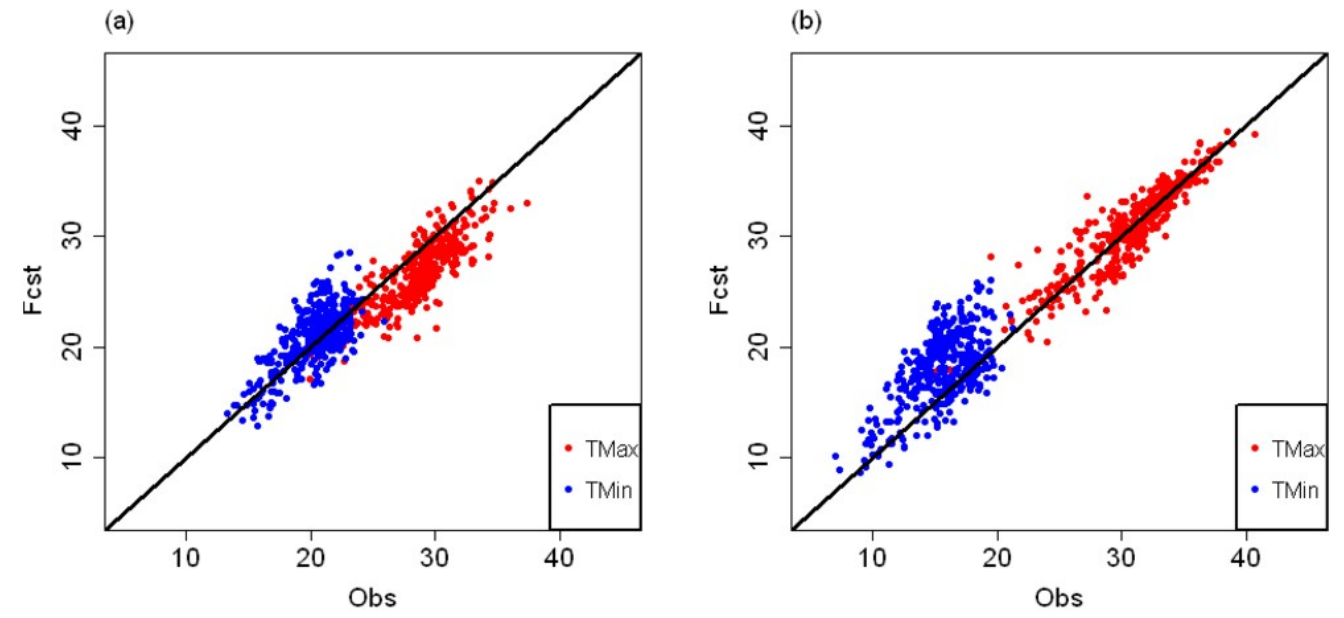

(c)

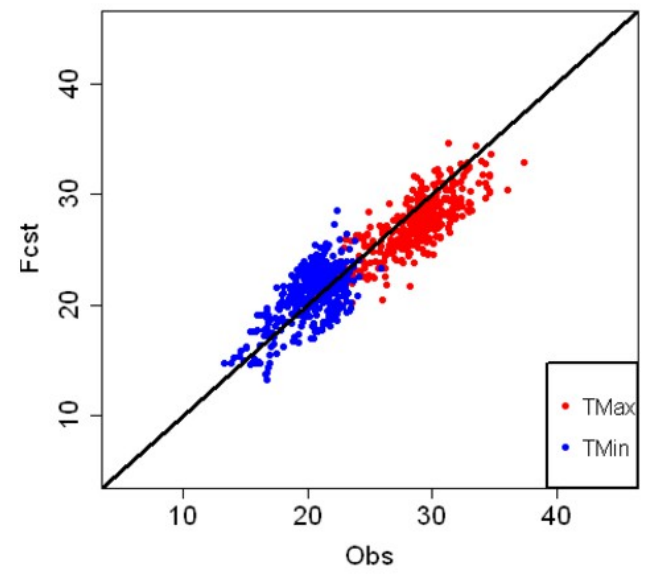

(e)

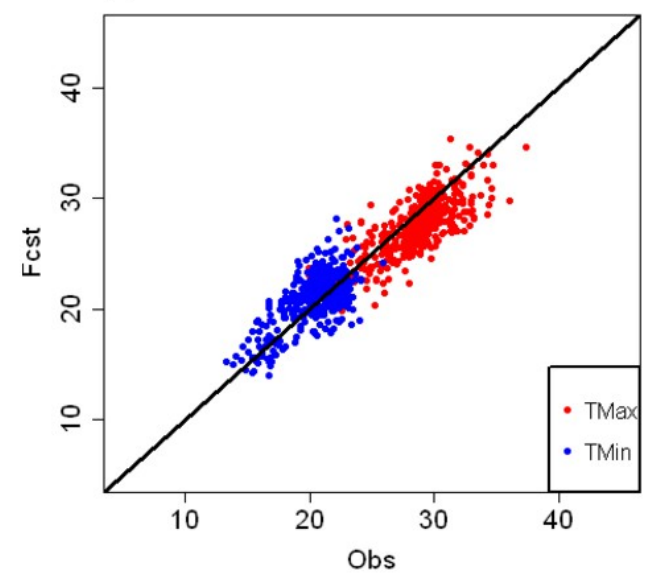

(d)
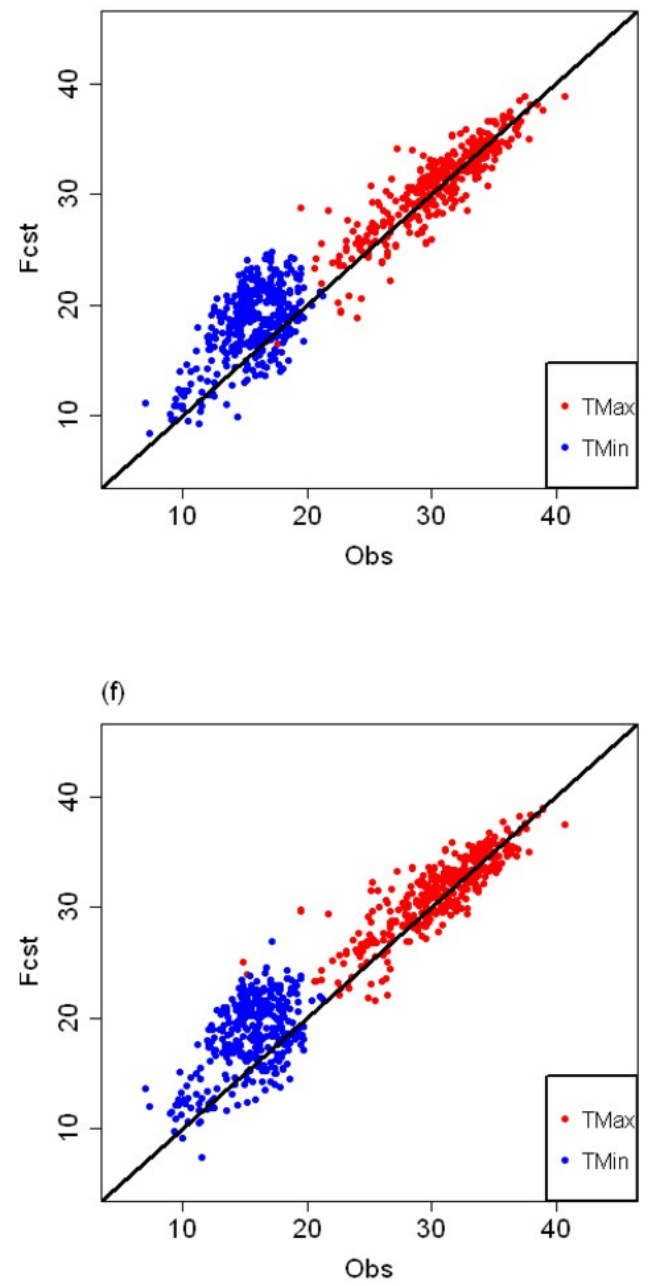

Figure 7 
(a)

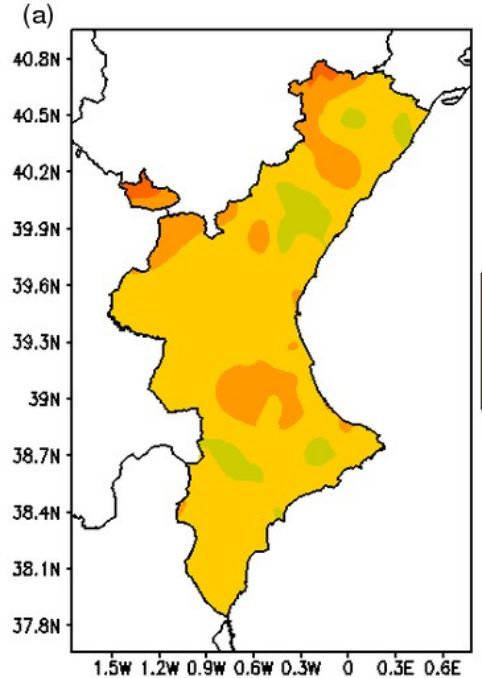

(c)

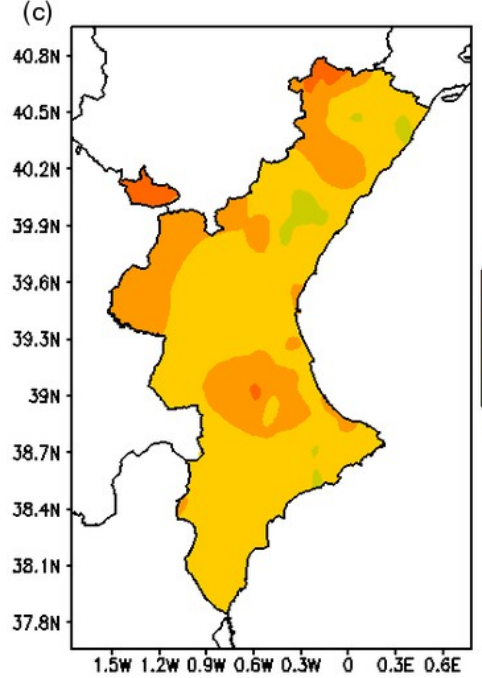

(e)

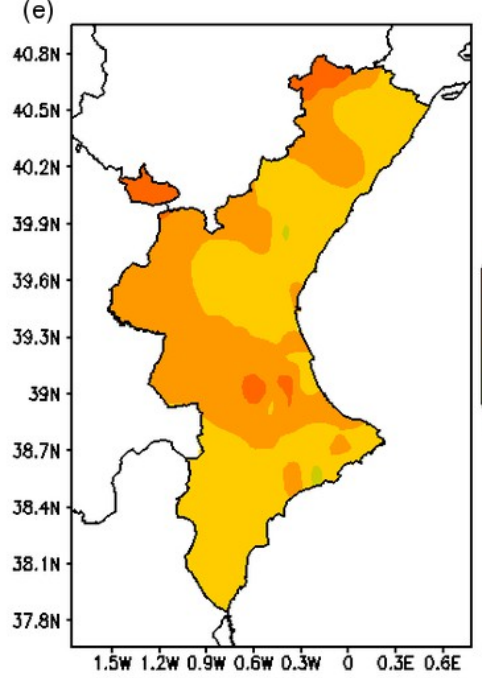

(b)

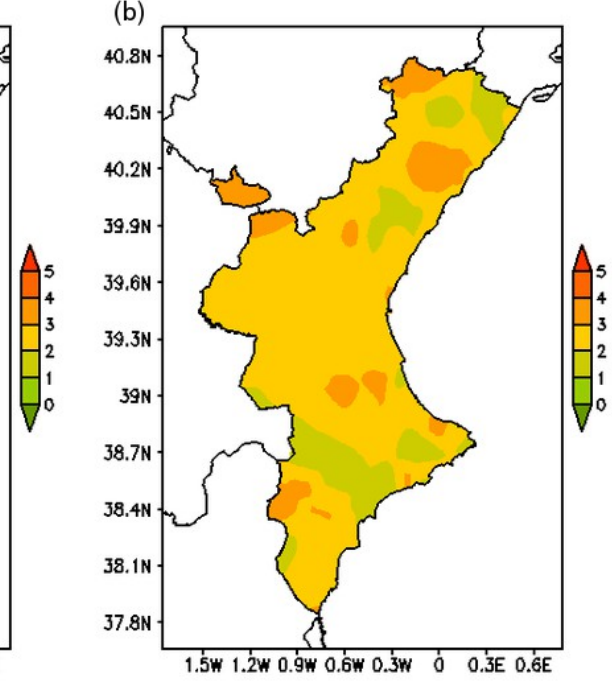

(d)
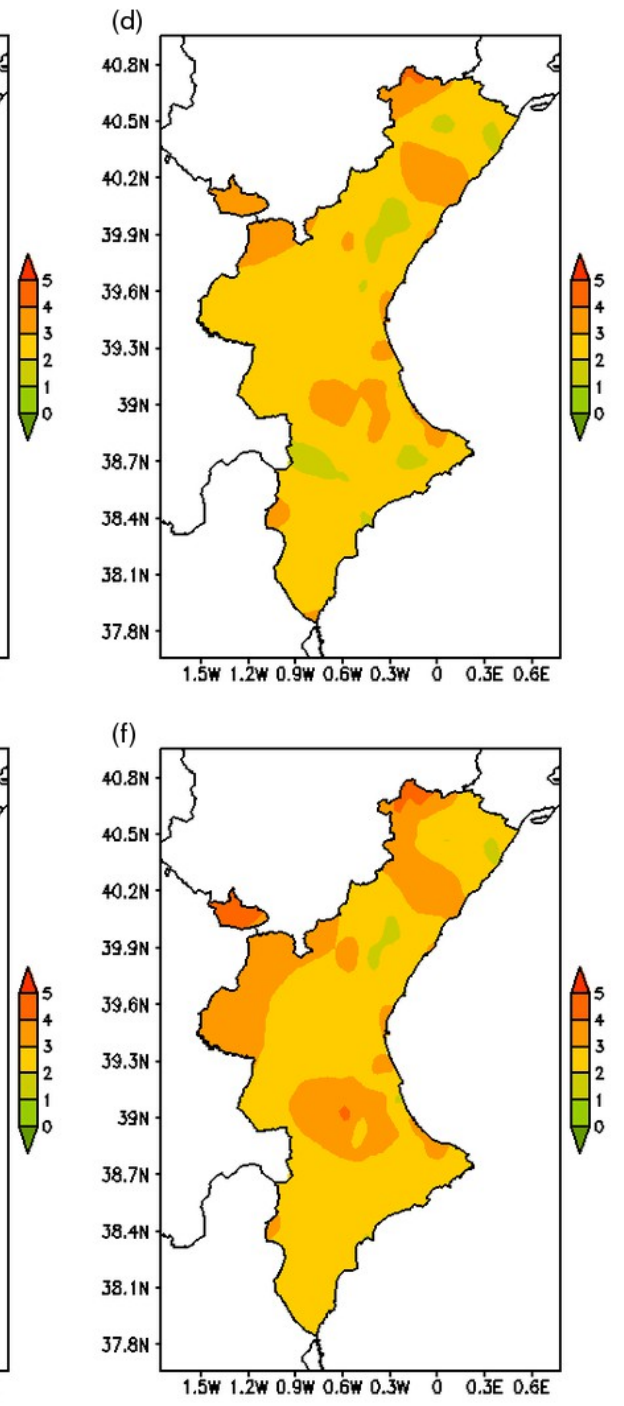

Figure 8 
(a)

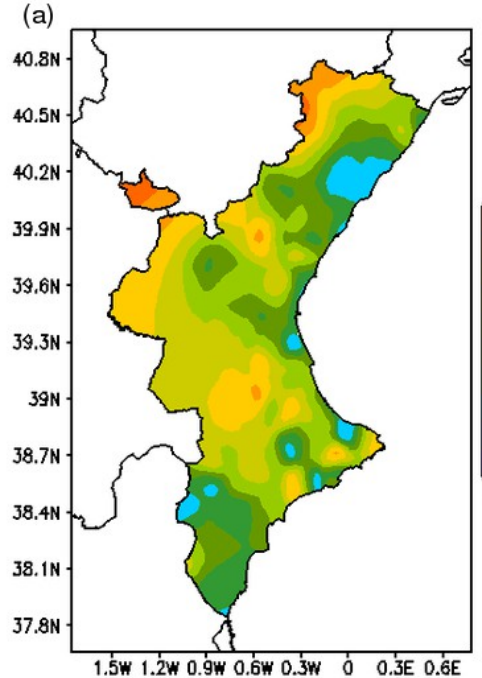

(c)

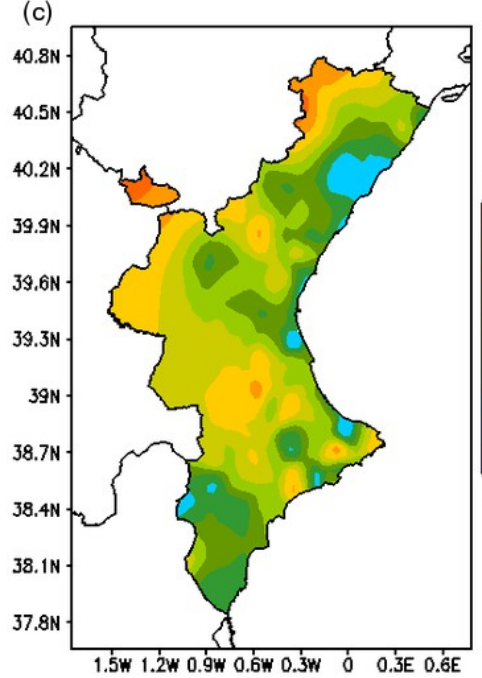

(e)

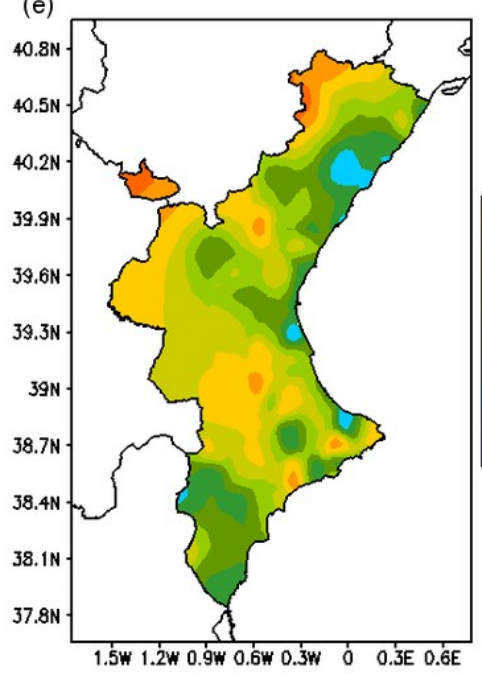

(b)

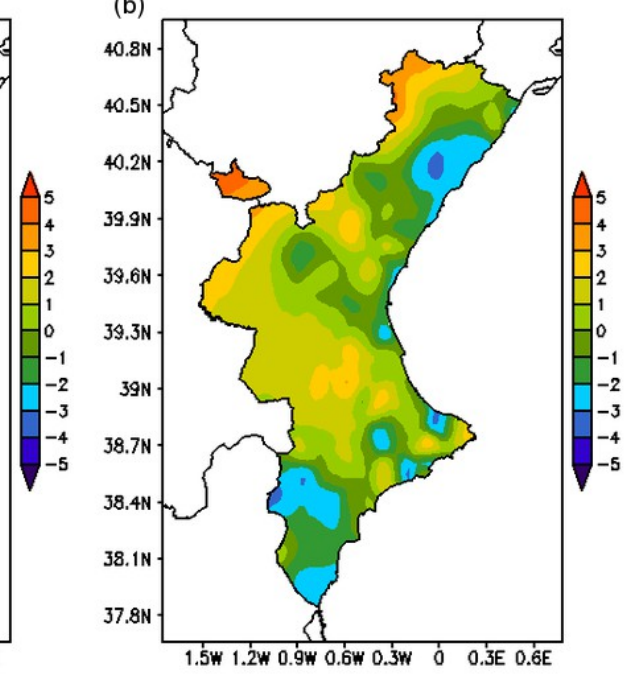

(d)
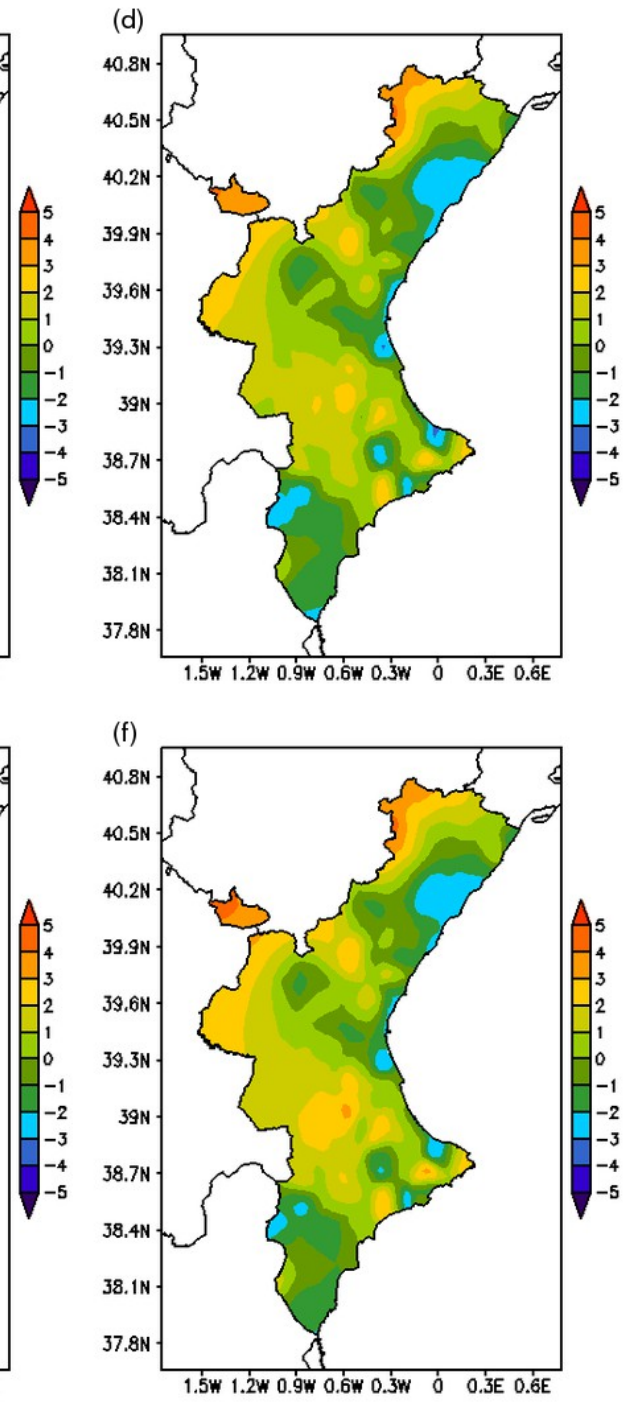

Figure 9 
(a)

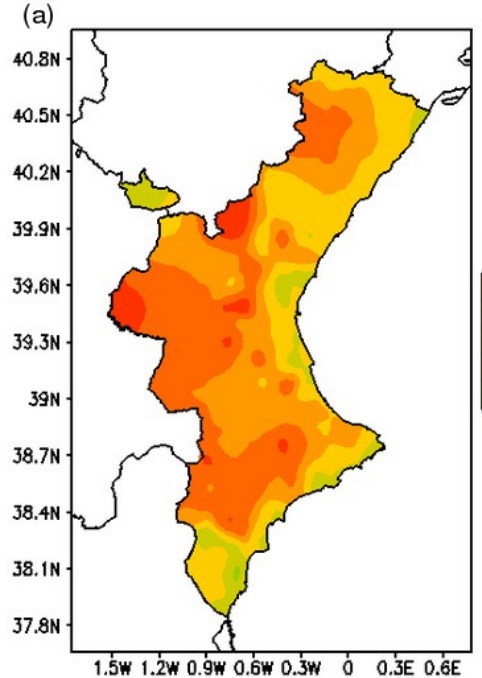

(c)

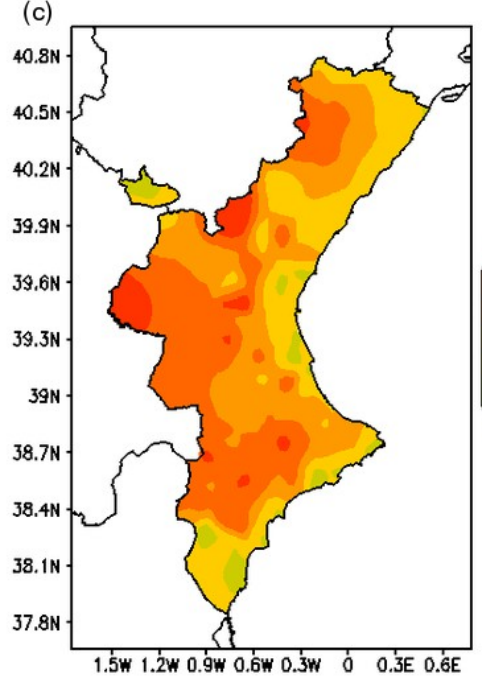

(e)

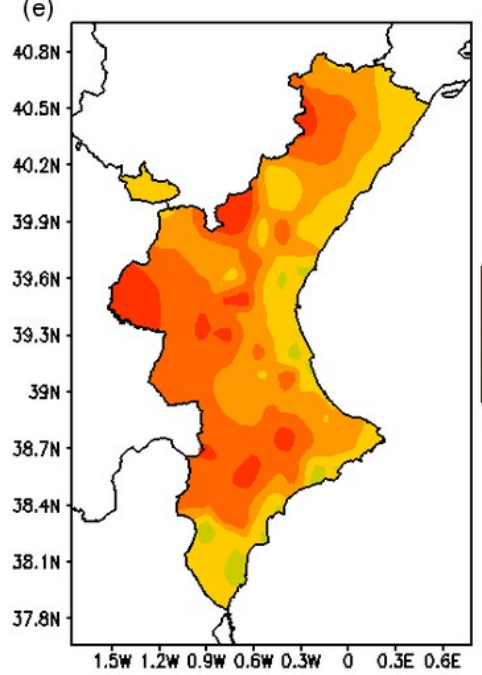

(b)

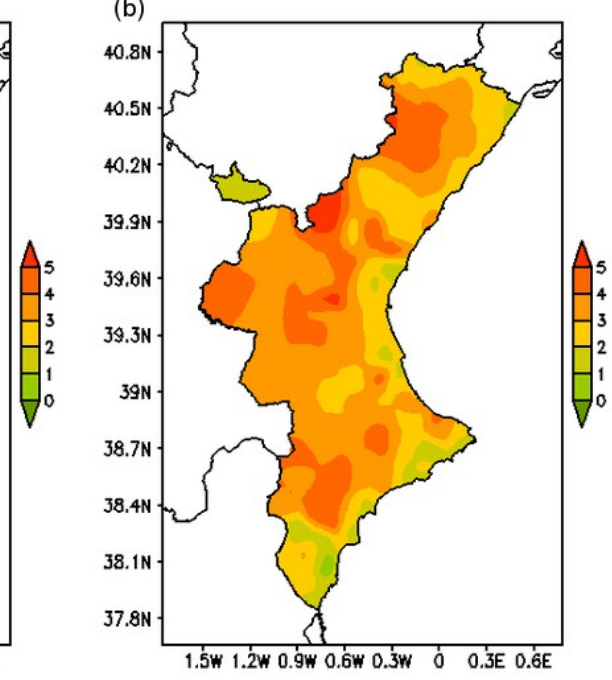

(d)
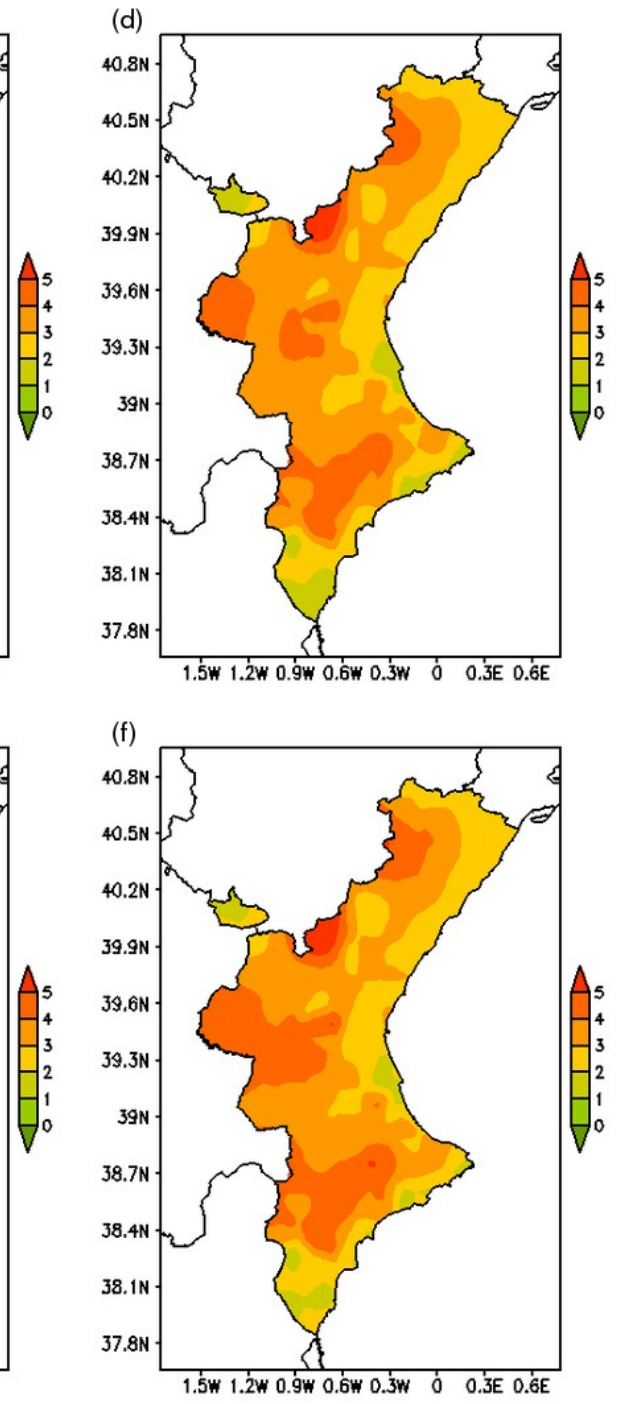

Figure 10 
(a)

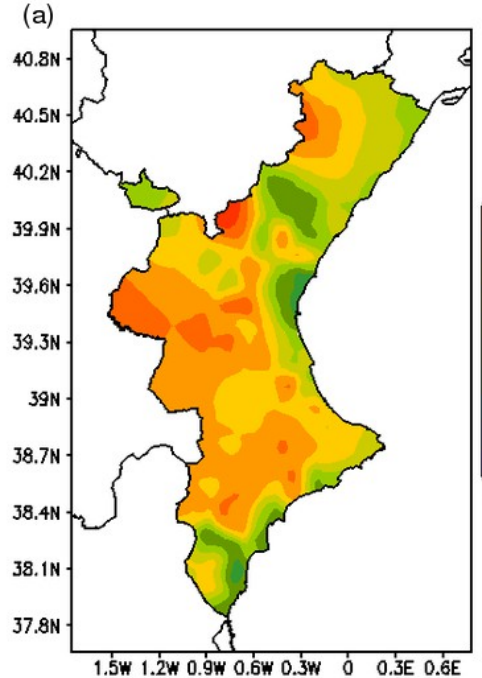

(c)

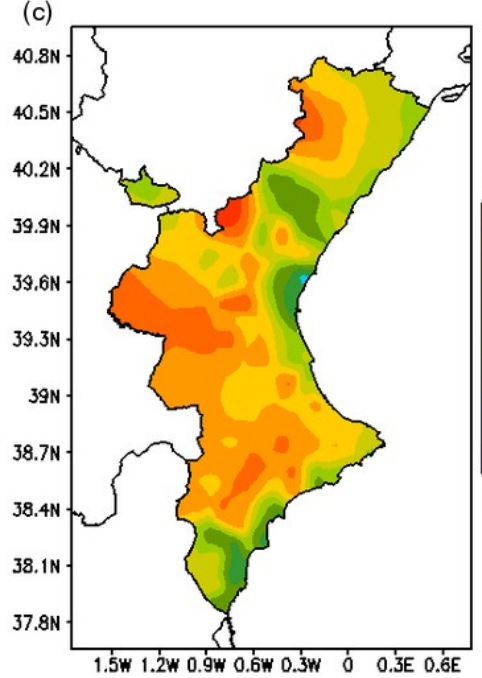

(e)

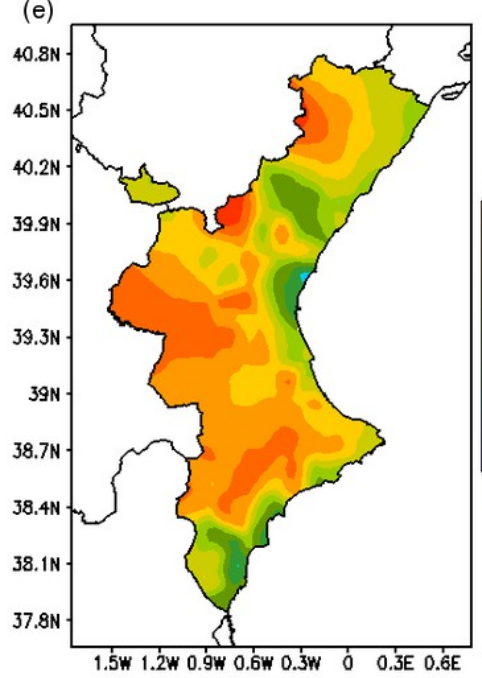

(b)

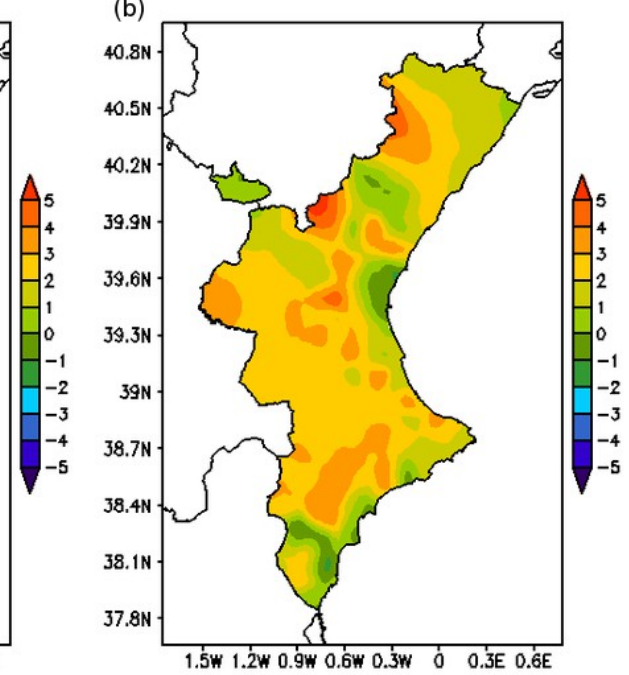

(d)
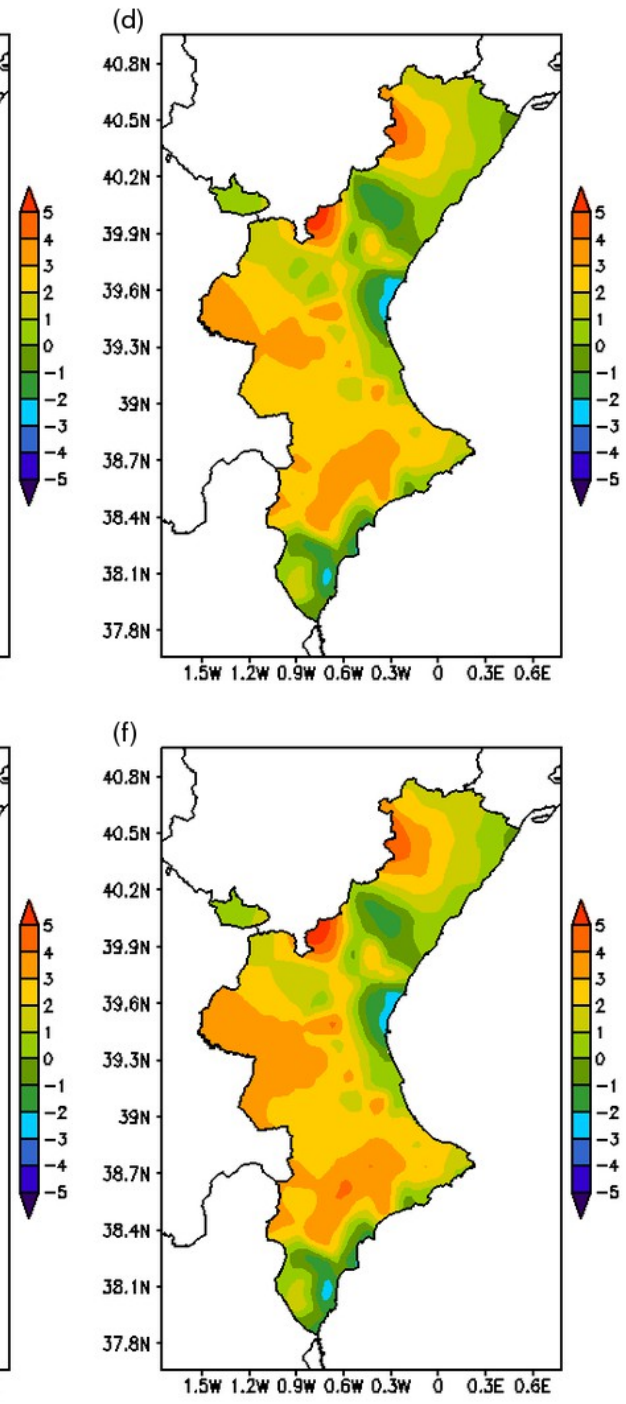

Figure 11 
